\title{
Impact of multi-functional fermented goat milk beverage on gut microbiota in a dynamic colon model
}

\author{
Fernanda Campos Freire ${ }^{\mathrm{a}}$, Maria Angela Tallarico Adorno ${ }^{\mathrm{b}}$, Isabel Kimiko Sakamoto ${ }^{\mathrm{b}}$, \\ Rosemar Antoniassi ${ }^{c}$, Ana Carolina Sampaio Dória Chaves ${ }^{c}$, Karina Maria Olbrich dos Santos ${ }^{c}$, \\ Katia Sivieri $^{\mathrm{a}, *}$ \\ a Department of Nutrition and Food Studies, School of Pharmaceutical Sciences, São Paulo State University (UNESP), Araraquara, São Paulo, Brazil \\ b Department of Hydraulic Engineering and Sanitation, São Carlos School of Engineering, University of São Paulo (USP), São Carlos, São Paulo, Brazil \\ ${ }^{\mathrm{c}}$ Brazilian Agricultural Research Corporation (EMBRAPA), Rio de Janeiro, Rio de Janeiro, Brazil
}

\section{A R T I C L E I N F O}

\section{Keywords:}

Functional foods

Probiotics

Prebiotics

Grape pomace

Phenolic compounds

SHIME ${ }^{\circledR}$

\begin{abstract}
A B S T R A C T
The aim of this research was to evaluate the effect of grape probiotic fermented beverages made of goat milk, with or without added grape pomace on gut microbiota in a Simulator of Human Intestinal Microbial Ecosystem (SHIME $^{\circledast}$ ). SHIME ${ }^{\circledR}$ model was used to investigate to assess changes in microbial composition and fermentation metabolites (short- and branched-chain fatty acids and ammonium), as well as under the antioxidant capacity. The results demonstrated that the beverages formulated, with or without grape pomace extract, exhibited high dietary fiber, oleic acid, phenolic compounds content and antioxidant activity. Both beverages also kept $L$. rhamnosus and $S$. thermophilus viable during their passage through the intestinal tract and had a positive effect on gut microbiota metabolism, increasing the antioxidant capacity and the production of short-chain fatty acids, and decreasing the ammonium concentration. Therefore, the multifunctional beverages formulated in this study can offer a new perspective for the production of foods with positive potential effects on human health.
\end{abstract}

\section{Introduction}

Gut microbiota is composed of a diversity of microorganism species that vary along the digestive tract and between individuals (Roberfroid et al., 2010). It is estimated that the intestinal tract is inhabited by $10^{11}$ cells/mL of luminal content, including 400 to 500 bacterial species (Scott, Gratz, Sheridan, Flint, \& Duncan, 2013). The microbiota is responsible for protecting the intestinal mucous membrane against pathogenic microorganisms (Lourens-Hattingh \& Viljoen, 2001), synthesizing vitamins K, B1, B2 and B12 (Saad, 2006), breaking down the nondigestible components of food and producing metabolites such as shortchain fatty acids (SCFAs) (Ríos-Covián et al., 2016).

Microbiota metabolism and composition are mainly influenced by the use of antibiotics, genetic and immunologic factors and by diet (Scott et al., 2013; Wu et al., 2012). It is known that the ingestion of probiotic microorganisms, prebiotic ingredients or symbiotic combinations is strongly associated with the regulation of gut microbiota (Gibson \& Roberfroid, 1995; Scott et al., 2013). Probiotics are living microorganisms which, when administered in adequate quantities, provide the host with health benefits (Hill et al., 2014). Probiotics can stimulate the immune system and promote digestive resistance to colonization by pathogens through the production of antimicrobial compounds (Sanders, 2003). The main probiotic strains used in functional foods belong to genus Lactobacillus spp. and Bifidobacterium spp. (Hervert-Hernández, Pintado, Rotger, \& Goñi, 2009). However, studies on probiotic Lactobacillus rhamnosus strains in the process of fermentation of lactic products are scarce (Jia, Chen, Chen, \& Ding, 2016). Some studies suggest that $L$. rhamnosus strains have the ability to survive stomach conditions and colonize the digestive tract of children and adults (Goldin et al., 1992; Millar, Bacon, Smith, Walker, \& Hall, 1993; Saxelin, Ahokas, \& Salminen, 1993). They have also been found to be able to restore the urinary and genital tract's microbiota and to reduce the risk of urinary tract infections (Reid, Beuerman, Heinemann, \& Bruce, 2001; Reid \& Bruce, 2003).

Prebiotics are non-digestible ingredients that are able to be fermented in the colon, stimulating the growth of beneficial bacteria and altering gut microbiota in favor of a healthier composition (Gibson \& Roberfroid, 1995). Furthermore, studies indicate that foods rich in phenolic compounds also could have a significant impact on gut microbiota (Kemperman et al., 2013). When present in the colon, these

\footnotetext{
* Corresponding author at: Department of Nutrition and Food Studies, School of Pharmaceutical Sciences, São Paulo State University (UNESP), Rodovia Araraquara-Jaú Km 1, 14801902 Araraquara, São Paulo, Brazil.

E-mail address: sivierik@fcfar.unesp.br (K. Sivieri).
} 
compounds can be metabolized by resident microbiota, leading to the production of biologically active metabolites (Van Duynhoven et al., 2011). These metabolites could influence the composition and activity of intestinal bacteria populations by stimulating or inhibiting specific groups and, as a consequence, regulating the microbiota (Kemperman, Bolca, Roger, \& Vaughan, 2010).

Probiotic microorganisms are usually vehicle by dairy products, such as fermented milk and yogurts (Hekmat, Soltani, \& Reid, 2009). However, the use of alternative food matrices, such as goat milk, could be a good option for the production of functional foods, particularly, for individuals that cannot ingest bovine dairy products due to the milk protein allergies (dos Santos et al., 2016; Silanikove, Leitner, Merin, \& Prosser, 2010). Goat milk is more easily digested by humans than cow milk due to the dimensions of the casein micelles and fat globules (Park, 2007). It also presents an oligosaccharide profile similar to human milk, a larger proportion of short- and medium-chain fatty acids, and a low allergenic potential (Lara-Villoslada et al., 2006; Minervini, Bilancia, Siragusa, Gobbetti, \& Caponio, 2009; RaynalLjutovac, Lagriffoul, Paccard, Guillet, \& Chilliard, 2008).

One interesting option in the development of functional foods is the use of fibers and bioactive compounds from agricultural industry waste. Conveniently, the wine industry processes approximately 50 million tons of grapes every year, and, in doing so, produces 5 to 9 million tons of grape pomace after fermentation (Djilas, ČanadanovićBrunet, \& Ćetković, 2009). Grape pomace is largely composed of seeds and skins. It is an important byproduct, rich in fiber and with a relevant concentration of phenolic compounds (Cataneo, Caliari, Gonzaga, Kuskoski, \& Fett, 2008). The fibers present in grape pomace can have a prebiotic effect on the intestinal mucous membrane, as has been demonstrated by Pozuelo et al. (2012).

Currently, much of the agro-industrial waste is disposed of in the natural environment or is treated as a product of low economic value, being often used as animal feed or fertilizer (de Campos, Leimann, Pedrosa, \& Ferreira, 2008). However, many benefits to human health can be attributed to the phenolic compounds present in grape pomace, such as anthocyanins, flavonoids, phenolic acids, and resveratrol, due to antioxidant, anti-inflammatory, and cardio protective effects (Cataneo et al., 2008; Manach, Mazur, \& Scalbert, 2005; PuupponenPimiä et al., 2001). As a result, options for the use of grape pomace and its bioactive compounds in human food products are being investigated. In this context, foods with various components with bioactive properties can be considered "multifunctional" foods and can promote human health (dos Santos et al., 2016).

The objective of this study was to identify the main bioactive compounds present in a grape-flavored probiotic fermented beverage made of goat milk, with and without grape pomace extract and to evaluate their functional effects on the gut microbiota in a Simulator of Human Intestinal Microbial Ecosystem (SHIME ${ }^{\circledR}$ ). It was evaluated the survival of Lactobacillus rhamnosus after the passage through the simulated conditions of the stomach and the duodenum. SHIME ${ }^{\circledR}$ is an in vitro model that dynamically simulates the human digestive tract which has frequently been used in nutrition studies due to its usefulness in the analysis of intestinal microbial population activity and composition (Barroso et al., 2014; Bianchi et al., 2014; Molly, Woestyne, Smet, \& Verstraete, 1994; Possemiers, Marzorati, Verstraete, \& Van de Wiele, 2010; Sivieri et al., 2014; Van de Wiele, Boon, Possemiers, Jacobs, \& Verstraete, 2004).

\section{Material and methods}

\subsection{Preparation of the grape pomace extract}

Merlot grape pomace was obtained from the Casa Valduga vineyards in the state of Rio Grande do Sul, Brazil. The extraction was performed in a jacketed tank at $50{ }^{\circ} \mathrm{C}$, under mechanical agitation at $48 \mathrm{rpm}$ for $180 \mathrm{~min}$. A hydroalcoholic extract solution containing $30 \%$
Table 1

Ingredients used in the formulation of the fermented beverages studied.

\begin{tabular}{lll}
\hline Ingredient (\%) & Formulation 1 & Formulation 2 \\
\hline Goat milk (Rancho Grande, Brazil) & 73.00 & 67.00 \\
Sugar (União, Brazil) & 7.00 & 7.00 \\
Grape pomace extract (Embrapa Grape and & 0.00 & 6.00 \\
$\quad$ Wine, Brazil) & & 20.00 \\
Grape juice (Embrapa Grape and Wine, Brazil) & 20.00 & 200 \\
\hline
\end{tabular}

ethanol (v/v) was used at a 7:1 ratio (solvent: substrate). The solid fraction was separated using a basket centrifuge with a $150 \mu \mathrm{m}$ nylon mesh as a filter. The obtained extract was bottled in previously sanitized plastic canisters and stored at $-16 \pm 1{ }^{\circ} \mathrm{C}$.

The extract was then dried in a spray-dryer (Model B190, Buchi ${ }^{\circledR}$ ) using maltodextrin at a $10 \%$ concentration (MDE 5, Corn Products 1805) as an encapsulating agent. The extract was maintained under constant agitation at room temperature and was sent to the spray dryer's main chamber with a peristaltic pump at a rate of $0.9 \mathrm{~L} / \mathrm{h}$. The entry and exit temperatures used in the spray dryer were $180{ }^{\circ} \mathrm{C}$ and $70{ }^{\circ} \mathrm{C}$, respectively. It was employed a flow rate of 2.4 bar. The dehydrated extract was kept at $-16 \pm 1{ }^{\circ} \mathrm{C}$.

\subsection{Fermented beverages preparation}

The fermented beverages were produced at the Brazilian Agricultural Research Corporation (EMBRAPA) in Rio de Janeiro, Brazil. Two formulations were produced: fermented milk + grape juice (formulation 1) and fermented milk + grape pomace extract + grape juice (formulation 2) (dos Santos et al., 2016). The ingredients used in the beverages, and respective proportions, are presented in Table 1.

With the exception of the grape juice, the ingredients were blended until they became completely smooth. The mixture was pasteurized at $95 \pm 1{ }^{\circ} \mathrm{C}$ for $10 \mathrm{~min}$ in a water-bath (Spencer ${ }^{\circledR}$, Dubnoff). The temperature of the mixture was then reduced to $43 \pm 1{ }^{\circ} \mathrm{C}$ for the inclusion of the probiotic culture $\left(0.3 \%\right.$ of $L$. rhamnosus, Sacco ${ }^{\circledR}$, Brazil) and the starter culture $\left(0.04 \%\right.$ of $S$. thermophilus, DuPont ${ }^{\oplus}$, USA). The mixture was fermented in a BOD incubation chamber (MA1415/780, Marconi ${ }^{\oplus}$ ) at $43 \pm 1{ }^{\circ} \mathrm{C}$ until a pH of approximately 5.0 was reached (measured each $30 \mathrm{~min}$ ). The beverages were cooled to $5 \pm 1{ }^{\circ} \mathrm{C}$ for $24 \mathrm{~h}$. Then, the grape juice was added (EMBRAPA Grape and Wine, Brazil) in both formulations. The final products were packed in highdensity polyethylene bottles, and stored at $5 \pm 1{ }^{\circ} \mathrm{C}$ for 28 days.

\subsection{Physical and chemical characteristics of the fermented beverages}

\subsubsection{Determining $p H$ and titratable acidity}

The $\mathrm{pH}$ and titratable acidity of the fermented beverages were evaluated during the 28 days of refrigerated storage at $5 \pm 1{ }^{\circ} \mathrm{C}$ using the methods proposed by the Association of Analytical Communities (AOAC, 2012). The analyses were run in triplicate.

\subsubsection{Centesimal composition and total dietary fiber}

Moisture, ash, protein, fat, carbohydrates content, and total energy values, were determined using the methods proposed by the AOAC (2005). The total dietary fiber content and its fractions (soluble, insoluble, and lignin) were determined according to the methodology proposed by Mañas, Bravo, and Saura-Calixto (1994). The analyses were run in triplicate.

\subsubsection{Fatty acid profile analysis}

Milk fat was extracted according to the method proposed by AOAC (2012). The methyl esters were prepared using the method by Christie (1982). The fatty acid profiles were analyzed in an Agilent 1890 gas chromatographer equipped with a cast silicon capillary column (CP-Sil 
88, $100 \mathrm{~m} \times 0.25 \mathrm{~mm} \times 0.20 \mu \mathrm{m})$ and a flame ionization detector using the methodology proposed by Cruz-Hernandez et al. (2007). The analyses were run in triplicate.

\subsubsection{Extraction of phenolic compounds}

Polyphenols were extracted from the fermented beverages using

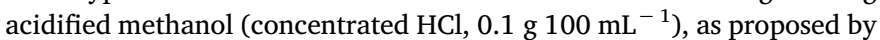
Karaaslan, Ozden, Vardin, and Turkoglu (2011), with slight modifications. Six milliliters of acidified methanol was added to each $1.5 \mathrm{~g}$ of the fermented beverages, and the samples were kept overnight at $4 \pm 1{ }^{\circ} \mathrm{C}$. The samples were later centrifuged at $1300 \mathrm{~g}$ at $4 \pm 1{ }^{\circ} \mathrm{C}$ for $15 \mathrm{~min}$. Next, $6 \mathrm{~mL}$ of acidified methanol was added to the precipitate, and the samples were centrifuged under the same conditions. The procedure was repeated two more times until a final volume of $24 \mathrm{~mL}$ was obtained. The obtained extracts were kept under $-16 \pm 1{ }^{\circ} \mathrm{C}$ and were used to determine the total phenolic compounds in the fermented beverages.

\subsubsection{Determining total phenolic compounds and antioxidant activity}

Total phenolic compounds were determined using the FolinCiocalteu reagent (Sigma ${ }^{\circledR}$, USA), according to Georgé, Brat, Alter, and Amiot (2005). The results were expressed as $\mathrm{mg}$ gallic acid equivalent (mg GAE $100 \mathrm{~g}^{-1}$ ). The antioxidant activity was determined using the $\mathrm{ABTS}^{+}$method proposed by Serpen, Capuano, Fogliano, and Gökmen (2007), and the results were expressed as mmol Trolox equivalent (mmol TE $\mathrm{g}^{-1}$ ).

\subsection{The dynamic colon fermentation model - Simulator of Human Intestinal Microbial Ecosystem (SHIME ${ }^{\circledast}$ )}

SHIME $^{\circledR}$ is a dynamic model of the human intestinal tract. It's composed of five connected reactors that represent the stomach (S), the duodenum (D), the ascending colon (AC), the transverse colon (TC), and the descending colon (DC), with their respective $\mathrm{pH}$ values, residence times, temperatures, and volume capabilities (Molly et al., 1994; Possemiers, Verthé, Uyttendaele, \& Verstraete, 2004).

At the beginning of the experiments, the AC, TC and DC simulation reactors were inoculated with non-gas producing (methane $<3 \mathrm{ppm}$ ) stool samples from three adult volunteers who had not taken antibiotics in the two years prior. The stool inoculum was prepared using the method by Possemiers et al. (2010). The inoculum was stabilized for two weeks in a carbohydrate-based medium, as previously described by Possemiers et al. (2004), so that the microbial community could adapt to the specific conditions within each reactor simulating the different regions of the colon.

The experimental set up of the SHIME ${ }^{\circledR}$ assay included a two-week stabilization period, a two-week control period, and a two-week treatment period, as previously described by Chaikham and Apichartsrangkoon (2014). During the treatment periods, $200 \mathrm{~mL}$ of the formulations 1 or 2 were added to the system once a day (containing $7 \log \mathrm{CFU} \mathrm{mL} \mathrm{m}^{-1}$ of $L$. rhamnosus and $S$. thermophilus) and $200 \mathrm{~mL}$ of the carbohydrate-based medium was added twice a day. During the control periods, only the carbohydrate-based medium was added to the system ( $200 \mathrm{~mL}$ three times a day). Fig. 1 shows the experimental protocol used in the SHIME ${ }^{\circledR}$.

All reactors were kept at $37{ }^{\circ} \mathrm{C}$ under magnetic stirring. The system was kept under anaerobiose through daily 30-minute injections of nitrogen. The $\mathrm{pH}$ of the reactors that simulate the stomach and AC, TC, and DC was controlled by automatically adding sodium hydroxide $1 \mathrm{~N}$ or hydrochloridric acid $1 \mathrm{~N}$ (Molly et al., 1994; Possemiers et al., 2004). In addition, $60 \mathrm{~mL}$ of artificial pancreatic juice $\left(12.5 \mathrm{~g} / \mathrm{L}\right.$ of $\mathrm{NaHCO}_{3}$, $6 \mathrm{~g} / \mathrm{L}$ of Oxgall and $1.9 \mathrm{~g} / \mathrm{L}$ of pancreatin) was added to the reactor simulating the duodenum at a rate of $4 \mathrm{~mL} / \mathrm{min}$ for $15 \mathrm{~min}$ (Molly et al., 1994; Possemiers et al., 2004).

2.4.1. Survival of L. rhamnosus and S. thermophilus under the simulated conditions of the stomach and duodenum in the SHIME ${ }^{\circledR}$

During the treatment period with the fermented beverages, samples were collected from the reactors corresponding to the stomach and duodenum in order to verify the survival of L. rhamnosus and $S$. thermophilus. One milliliter of samples from each reactor was suspended in $9 \mathrm{~mL}$ of sterile peptone water and serial dilutions were carried. $L$. rhamnosus was plated in MRS agar (Merck ${ }^{\circledast}$, Germany) acidified to pH 5.4 and incubated under anaerobiose (Probac, Brazil) at $37 \pm 1{ }^{\circ} \mathrm{C}$ for $72 \mathrm{~h}$ (Oliveira, Sodini, Remeuf, \& Corrieu, 2001). S. thermophilus was plated in M17 agar (Oxoid ${ }^{\oplus}$, United Kingdom) containing lactose $(5.0 \mathrm{~g} / \mathrm{L})$, and incubated under anaerobiose (Probac, Brazil) at $37 \pm 1{ }^{\circ} \mathrm{C}$ for $48 \mathrm{~h}$ (Cardarelli, Buriti, Castro, \& Saad, 2008).

\subsubsection{Microbiological analysis of the SHIME ${ }^{\circledR}$ samples}

Changes in the gut microbiota during the experimental protocol were determined based on the enumeration of the populations of Lactobacillus spp., Bifidobacterium spp., Clostridium spp., total anaerobes and total coliforms. The sampling was made after 7 days of each experimental period (control and treatment periods). One milliliter of samples from each reactor was suspended in $9 \mathrm{~mL}$ of sterile peptone water. Serial dilutions were prepared and inoculated in selective culture mediums (Table 2).

The behavior and diversity of total bacteria throughout during the experimental period was analyzed by PCR-DGGE. The DNA from the simulated colon reactor samples was extracted using the QIAamp DNA Stool Mini Kit (Qiagen, Germany), according to the producer's protocols, with slight modifications. The DNA was quantified using a NanoVue $^{\mathrm{TM}}$ Plus (GE Healthcare, USA) spectrophotometer. The primers used to replicate the DNA were 968FGC (5'-CGC CCG GGG CGC GCC CCG GGC GGG GCG GGG GCA CGG GGG GAA CGC GAA GAA CCT TAC$3^{\prime}$ ) and 1401R (5-CGG TGT GTA CAA GAC CC-3') (Engelen et al., 1996). DNA polymerization was performed using a GoTaq ${ }^{\circledR}$ Green Master Mix (Promega, USA). The samples were then amplified in a thermal cycler (Applied Biosystems, USA) under the following conditions: initial denaturation at $95{ }^{\circ} \mathrm{C} / \mathrm{min}, 35$ denaturation cycles at $94^{\circ} \mathrm{C} / 45 \mathrm{~s}$, annealing at $56^{\circ} \mathrm{C} / 45 \mathrm{~s}$, extension at $72{ }^{\circ} \mathrm{C} / \mathrm{min}$ and final extension at $72{ }^{\circ} \mathrm{C} / 10 \mathrm{~min}$, followed by cooling at $4{ }^{\circ} \mathrm{C}$.

Electrophoresis was performed in an $8 \%$ polyacrylamide gel with a

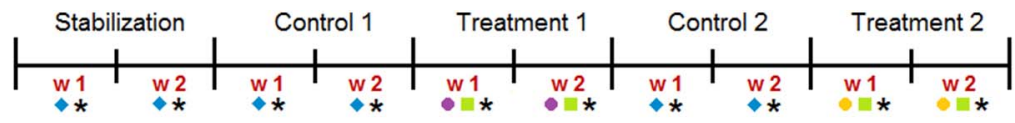

w 1 Week 1

w 2 Week 2

$\downarrow$ Carbohydrate-based medium $(200 \mathrm{~mL} / 3 x$ day)

- Fermented goat milk + grape juice $(200 \mathrm{~mL} / 1 \mathrm{x}$ day $)+$ carbohydrate-based medium $(200 \mathrm{~mL} / 2 \mathrm{2}$ day $)$

- Survival of $L$. rhamnosus and $S$. thermophilus under simulated stomach and duodenum conditions

- Fermented goat milk + grape pomace extract + grape juice $(200 \mathrm{~mL} / 1 \mathrm{x}$ day $)+$ carbohydrate-based medium $(200 \mathrm{~mL} / 2 \mathrm{x}$ day $)$

* Microbiological (plate count and molecular analysis), $\mathrm{NH}_{4}^{+}$, short and branched chain fatty acids and antioxidant capacity analysis
Fig. 1. Experimental protocol used in the Simulator of the Human Intestinal Microbial Ecosystem (SHIME ${ }^{\circledast}$ ). 
Table 2

Culture media and conditions used in the microbiological analysis in the SHIME ${ }^{\circledR}$.

\begin{tabular}{|c|c|c|c|c|c|}
\hline Genus & Culture medium & Brand & Time/temperature & Oxygen condition & Reference \\
\hline Lactobacillus spp. & Agar MRS & Himedia (India) & $37^{\circ} \mathrm{C} / 48 \mathrm{~h}$ & Anaerobiose & Yoshioka et al. (1983) \\
\hline Bifidobacterium spp. & Agar BIM-25 & Difco (France) & $37^{\circ} \mathrm{C} / 72 \mathrm{~h}$ & Anaerobiose & Munoa \& Pares (1988) \\
\hline Clostridium spp. & Agar RCA & Difco (France) & $37^{\circ} \mathrm{C} / 48 \mathrm{~h}$ & Anaerobiose & Marzotto et al. (2006) \\
\hline Total anaerobes & Agar Standard Methods & Acumedia (USA) & $37^{\circ} \mathrm{C} / 48 \mathrm{~h}$ & Anaerobiose & Yoshioka et al. (1983) \\
\hline Total coliforms & Petrifilm $^{\mathrm{TM}}$ EC plaques & $3 \mathrm{M}$ & $37^{\circ} \mathrm{C} / 48 \mathrm{~h}$ & Aerobiose & \\
\hline
\end{tabular}

denaturation gradient between $45 \%$ and $65 \%$ for $16 \mathrm{~h}$ at $75 \mathrm{~V}$ in a TAE $1 \times$ buffer at a constant temperature of $60{ }^{\circ} \mathrm{C}$ (dos Reis, Carosia, Sakamoto, Varesche, \& Silva, 2015). The gels were dyed with ethidium bromide (Sanguinetti, Dias Neto, \& Simpson, 1994), digitized (400 dpi) and later analyzed using the BioNumerics software, version 6.0 (Applied Maths, Belgium).

The ecological analysis (richness and functional organization) was performed based on the study by Marzorati, Wittebolle, Boon, Daffonchio, and Verstraete (2008). Richness (Rr) is correlated with the distribution patterns of the DGGE bands, and with the percentage of denaturing gradient gel required to represent the total diversity of the sample. This concept can be mathematically expressed using the index $\mathrm{Rr}=\left(\mathrm{N}^{2} \times \mathrm{Dg}\right)$, where $\mathrm{N}$ represents the total number of bands in the DGGE line and where Dg represents the denaturing gradient present between the first and last bands.

Pareto-Lorenz distribution curves were created in order to represent the structure and functionality of bacterial communities based on the DGGE profiles (Mertens, Boon, \& Verstraete, 2005; Wittebolle, Vervaeren, Verstraete, \& Boon, 2008). The respective bands are classified from high to low for each DGGE line according to their intensity. The cumulative value of the $\mathrm{Y}$ axis (in this case, the intensity proportion of the bands) corresponds to $20 \%$ of the cumulative proportion of the evaluated species ( $\mathrm{X}$ axis). The more deviation is shown by the ParetoLorenz curve from the theoretical perfect line (that is, $45^{\circ}$ ), the less uniform the structure of the microbial community studied is. Low uniformity means that few different species are present in dominant quantities (Dejonghe, Boon, Seghers, Top, \& Verstraete, 2001; Mertens et al., 2005; Wittebolle et al., 2008).

2.4.3. Ammonium $\left(\mathrm{NH}_{4}{ }^{+}\right)$and short- and branched-chain fatty acids (SCFAs and BCFAs) analysis

Samples from the colon simulating reactors were collected in each experimental period (controls 1 and 2, and treatments 1 and 2), and stored at $-20{ }^{\circ} \mathrm{C}$. The production of $\mathrm{NH}_{4}{ }^{+}$was determined using anion measurer attached to an ion-selective electrode (Model No. 95-12, Orion) according to Bianchi et al. (2014). The device was calibrated with standard solutions of ammonium chloride at $0.1 \mathrm{M}$ in concentrations of 10,100 and $1000 \mathrm{mg} / \mathrm{L}$ of ammonium. A total of $0.2 \mathrm{~mL}$ of ISA (Orion) solution was added to each $10 \mathrm{~mL}$ of sample material.

For the SCFAs and BCFAs analysis, $2 \mathrm{~mL}$ of samples were centrifuged at $13,000 \mathrm{~g}$ for $5 \mathrm{~min}$. Then, $100 \mu \mathrm{L}$ of the supernatant was diluted in $1900 \mathrm{~mL}$ of ultrapure water, $1 \mathrm{~g}$ of sodium chloride, $100 \mathrm{~mL}$ of chrotonic acid, $70 \mathrm{~mL}$ of isobutanol, and $200 \mu \mathrm{L}$ of sulphuric acid (2 M). The SCFAs were analyzed in a Model-2010 gas chromatographer (Shimadzu, Japan) equipped with a split/splitless injector and a flame ionization detector. The SCFAs were separated using an HP-Innowax (30 $\mathrm{m} \times 0.25 \mathrm{~mm} \times 0.25 \mu \mathrm{m})$ column (Agilent Technologies, USA). The transporting gas used was hydrogen, and the flow rate was $1.45 \mathrm{~mL} / \mathrm{min}$. The temperature of both the injector and the detector was $240{ }^{\circ} \mathrm{C}$ (Adorno, Hirasawa, \& Varesche, 2014).

\subsubsection{Antioxidant capacity of the SHIME ${ }^{\circledast}$ samples}

The antioxidant capacity of the reactor samples simulating the AC, TC, and DC were determined throughout the experimental period according to the method proposed by Re et al. (1999). An aliquot of $30 \mu \mathrm{L}$ of each sample was mixed with $3 \mathrm{~mL}$ of $\mathrm{ABTS}^{+}$, and the absorbance was measured at $734 \mathrm{~nm}$ in a SP-220 spectrophotometer (Biospectro, Brazil).

\subsection{Statistical analysis}

Data had a homoscedastic normal distribution and the results obtained were expressed as mean \pm standard deviation. Analysis of variance (ANOVA) and Tukey's test were performed to evaluate the survival of $L$. rhamnosus and $S$. thermophilus under simulated stomach and duodenum conditions in the SHIME ${ }^{\circledast}$. Student's $t$-test $(\mathrm{p} \leq 0.05)$ was applied for comparison between control and treatment periods in each reactor that simulates the colon (AC, TC and DC).

A principal component analysis (PCA) was performed to better understand the results found in the SHIME $^{\circledR}$ during the treatment periods. The variables studied were organized in columns (variables) and the experimental periods were organized into lines (cases). Before the analysis, the data was normalized and the PCA was performed with a correlation matrix and without a rotation factor. All analyses were performed in Statistica 10.0 software (StatSoft ${ }^{\circledR}$ Inc., USA).

\section{Results and discussion}

\subsection{Physical and chemical characteristics of the fermented beverages}

\subsection{1. $p H$ and titratable acidity}

The $\mathrm{pH}$ values of the formulated beverages did not vary during the storage period. Formulations 1 and 2 presented mean $\mathrm{pH}$ levels of 4.30 and 4.31 , respectively, over the 28 days of storage at $5 \pm 1{ }^{\circ} \mathrm{C}$. The titratable acidity of formulation $2\left(0.61 \pm 0.01{\left.\mathrm{~g} 100 \mathrm{~g}^{-1}\right) \text { was higher }}^{-1}\right.$

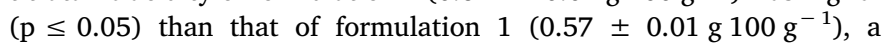
finding which was likely due to the addition of grape pomace extract, which presented a pH of 3.80. dos Santos et al. (2016) developed a probiotic fermented goat milk product, using grape pomace extract, and

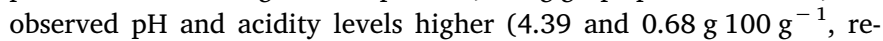
spectively) than those described in this study. According to the Brazilian Technical Regulations for the Identity and Quality of Fermented

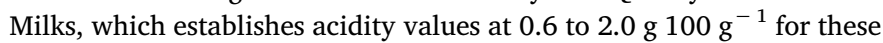
products, all of the fermented beverages produced herein adhered to Brazilian legislation.

\subsubsection{Centesimal composition and fatty acids profile}

Table 3 shows the centesimal composition of the fermented beverages. Statistical differences between the two formulations were detected for all parameters, with the exception of the fat content. dos Santos et al. (2016) and Salva et al. (2011) developed fermented beverages made of goat milk with Lactobacillus rhamnosus, and both studies found centesimal composition values similar to those found in this study.

In the current study, the added grape pomace extract contributed to a higher dietary fiber content in formulation 2. However, both formulations adhere to current Brazilian laws and are classified as foods with high dietary fiber content in a daily portion of fermented milk (formulation 1: $5.08 \mathrm{~g} \mathrm{200}^{-1}$ and formulation 2: $7.84 \mathrm{~g} \mathrm{200}^{-1}$ ). The consumption of dietary fiber is associated with several health 
Table 3

Centesimal composition, fatty acid profiles, and total phenolic compounds in the formulated fermented beverages (formulations 1 and 2 ).

\begin{tabular}{|c|c|c|c|}
\hline Parameter & Formulation 1 & Formulation 2 & $\mathrm{t}(\mathrm{p})$ \\
\hline $\mathrm{pH}$ & $4.30 \pm 0.01$ & $4.31 \pm 0.02$ & $-0.63(0.56)$ \\
\hline Titratable acidity $\left(\mathrm{g} 100 \mathrm{~g}^{-1}\right)$ & $0.57 \pm 0.01$ & $0.61 \pm 0.01$ & $-3.48(0.03)$ \\
\hline \multicolumn{4}{|l|}{ Centesimal composition } \\
\hline Moisture $\left({\left.\mathrm{g} 100 \mathrm{~g}^{-1}\right)}^{-1}\right.$ & $81.67 \pm 0.02$ & $78.36 \pm 0.06$ & $-85.94(<0.01)$ \\
\hline Ash $\left(\mathrm{g} 100 \mathrm{~g}^{-1}\right)$ & $0.76 \pm 0.01$ & $0.89 \pm 0.01$ & $31.84(<0.01)$ \\
\hline Total nitrogen $\left({\left.\mathrm{g} 100 \mathrm{~g}^{-1}\right)}\right.$ & $0.43 \pm 0.01$ & $0.47 \pm 0.01$ & $6.97(<0.01)$ \\
\hline Fat $\left(\mathrm{g} 100 \mathrm{~g}^{-1}\right)$ & $2.39 \pm 0.01$ & $2.38 \pm 0.02$ & $-0.42(0.70)$ \\
\hline Total dietary fiber $\left(\mathrm{g} 100 \mathrm{~g}^{-1}\right)$ & $2.54 \pm 0.01$ & $3.92 \pm 0.02$ & $-131.23(<0.01)$ \\
\hline Soluble fiber $\left(\mathrm{g} 100 \mathrm{~g}^{-1}\right)$ & $1.88 \pm 0.02$ & $2.18 \pm 0.01$ & $28.78(<0.01)$ \\
\hline Insoluble fiber $\left({\left.\mathrm{g} 100 \mathrm{~g}^{-1}\right)}^{-1}\right.$ & $0.20 \pm 0.01$ & $0.98 \pm 0.01$ & $-95.53(<0.01)$ \\
\hline Lignin $\left({\left.\mathrm{g} 100 \mathrm{~g}^{-1}\right)}^{-1}\right.$ & $0.45 \pm 0.01$ & $0.76 \pm 0.01$ & $-37.97(<0.01)$ \\
\hline Carbohydrate $\left({\left.\mathrm{g} 100 \mathrm{~g}^{-1}\right)}^{-1}\right.$ & $9.96 \pm 0.02$ & $11.45 \pm 0.01$ & $-141.67(<0.01)$ \\
\hline Total calories $\left(\mathrm{kcal}_{\left.100 \mathrm{~g}^{-1}\right)}\right.$ & $70.90 \pm 0.02$ & $94.90 \pm 0.01$ & $-2277.16(<0.01)$ \\
\hline \multicolumn{4}{|l|}{ Fatty acids ( $\mathrm{g} 100 \mathrm{~g}^{-1}$ fatty acid methyl esters) } \\
\hline Capric acid & $3.93 \pm 0.02$ & $2.91 \pm 0.01$ & $79.01(<0.01)$ \\
\hline Myristic acid & $10.43 \pm 0.02$ & $9.75 \pm 0.02$ & $47.03(<0.01)$ \\
\hline Palmitic acid & $26.17 \pm 0.01$ & $25.75 \pm 0.02$ & $40.16(<0.01)$ \\
\hline Stearic acid & $6.10 \pm 0.02$ & $6.51 \pm 0.01$ & $-32.87(<0.01)$ \\
\hline Oleic acid & $31.51 \pm 0.02$ & $33.07 \pm 0.02$ & $-124.54(<0.01)$ \\
\hline \multicolumn{4}{|c|}{ Branched-chain fatty acids ( $\mathrm{g} 100 \mathrm{~g}^{-1}$ fatty acid methyl esters) } \\
\hline Iso tetradecanoic acid & $0.15 \pm 0.03$ & $0.14 \pm 0.01$ & $-0.43(0.69)$ \\
\hline Pentadecanoic acid & $1.60 \pm 0.03$ & $1.52 \pm 0.02$ & $-4.13(0.01)$ \\
\hline Iso pentadecanoic acid & $0.34 \pm 0.02$ & $0.36 \pm 0.02$ & $-1.22(0.29)$ \\
\hline Anti-iso pentadecanoic acid & $0.63 \pm 0.01$ & $0.61 \pm 0.02$ & $1.55(0.20)$ \\
\hline Iso hexadecanoic acid & $0.37 \pm 0.01$ & $0.37 \pm 0.01$ & $0.00(1.00)$ \\
\hline Total phenolic compounds (mg GAE $100 \mathrm{~g}^{-1}$ ) & $53.16 \pm 3.14$ & $73.52 \pm 3.13$ & $-7.96(<0.01)$ \\
\hline Antioxidant activity (mmol $\mathrm{TE}^{-1}$ ) & $418.02 \pm 16.14$ & $743.78 \pm 23.88$ & $-15.98(<0.01)$ \\
\hline
\end{tabular}

Averages \pm standard deviation $(n=3)$; Student's $t$-test $(\mathrm{p} \leq 0.05)$.

benefits, including the regulation of gut microbiota through the increase in the population of commensal bacteria and the production of SCFAs, as well as colon cancer prevention, decreases in the duration of gut transit, and increases in the frequency of defecation (Anderson et al., 2009).

The fat in goat milk is synthesized in the alveoli of the mammary glands and involves the fatty acids present in the blood stream, which are a product of the fermentation that occurs in the rumen. They are composed of triglycerides and a large proportion of medium- and shortchain fatty acids (C 4:0-C 16:0) (Jenness, 1980). The fatty acids content in goat milk are different from those found in bovine milk, showing a higher proportion of capric acid (C 10:0), myristic acid (C 14:0), palmitic acid (C 16:0), stearic acid (C 18:0), and oleic acid (C 18:1), as well as branched-chain fatty acids (Ceballos et al., 2009; Park, 2007).

Some components of the lipid fraction may contribute to the prevention of certain diseases, in particular, cardiovascular diseases (Haenlein, 2004). In the current study, formulation 2 was found to have higher concentrations than formulation 1 ( $\mathrm{p} \leq 0.05)$ of oleic acid (C 18:1), stearic acid (C 18:0), and pentadecanoic acid (iso-C 15:0) (Table 3). Several studies suggest that dietary oleic acid (C 18:1), commonly known as $\omega-9$, reduces the risk of patients developing atherosclerosis due to its ability to decrease plasmatic cholesterol (Besler \& Grimble, 1995; Miles \& Calder, 1998; Yaqoob, 1998), induces anti-inflammatory effects in auto-immune diseases (Kremer et al., 1990; Linos et al., 1991), decreases blood pressure (Ferrara et al., 2000), and offer protective effects against breast cancer (Lipworth, Martínez, Angell, Hsieh, \& Trichopoulos, 1997; Martin-Moreno et al., 1994; Simonsen et al., 1998). Oleic acid intake recommendations are based on the recommendations for intakes of total fat (around 30\% of the total energy) and should be therefore in the range of $10-15 \%$ (LopezHuertas, 2010). All formulations studied showed concentrations of oleic acid according to the intake recommendations.

Stearic fatty acids (C 18:0) have no effect on plasmatic cholesterol; however, once ingested, they are metabolized into oleic acid (Griinari et al., 2000; Grummer, 1991; Matheson et al., 1996). Pentadecanoic acid, on the other hand, is a branched-chain fatty acid (BCFAs), and recent research suggests that its consumption is associated with certain health benefits, including gut microbiota control and an increase in anti-inflammatory cytokine expression (Ran-Ressler, Bae, Lawrence, Wang, \& Brenna, 2014).

Higher concentrations ( $\mathrm{p} \leq 0.05$ ) of capric acid (C 10:0), myristic acid (C 14:0) and palmitic acid (C 16:0) were observed in formulation 1. Capric acid is one of acids responsible for the peculiar smell of goat milk, which is traditionally described as "goaty" (Haenlein, 2004; Raynal-Ljutovac et al., 2008). From a nutrition point of view, myristic acid (C 14:0) and palmitic acid (C 16:0) are undesirable, because they are associated with an increase in plasmatic cholesterol (Grummer, 1991).

\subsubsection{Total phenolic compounds and antioxidant activity}

As Table 3 shows, adding grape pomace extract contributed to increase the level of phenolic compounds and antioxidant activity in formulation 2 ( $\mathrm{p} \leq 0.05)$. In this study, the total level of phenolic compounds in both formulations was higher than data reported in literature on fermented milks with added grape pomace (Chouchouli et al., 2013; dos Santos et al., 2016; Frumento et al., 2013; Karaaslan et al., 2011). Either the addition of grape juice (which was found to have $343.83 \pm 4.35 \mathrm{mg} \mathrm{GAE} 100 \mathrm{~g}^{-1}$ of polyphenols) or the type of grape used may have contributed to the higher value of phenolic compounds found in the beverages. Manach, Hubert, Llorach, and Scalbert (2009) suggest that daily consumption of polyphenols is $100-150 \mathrm{mg}$ for the western population. In this context, both formulations meet the daily consumption of polyphenols.

Other studies have also described an increase in antioxidant activity in yogurts with addition of grape pomace extract (Chouchouli et al., 2013; Karaaslan et al., 2011). Phenolic compounds have been attracting growing research due to their antioxidant, anti-inflammatory and antimutagenic properties. The antioxidant activity of these compounds involves the property of phenols to capture the more reactive varieties of oxygen and to inhibit the self-oxidant potential of cells (Antolovich, Prenzler, Robards, \& Ryan, 2000). Increases in oxidant stress may play a fundamental role in the development of chronic diseases, such as heart 


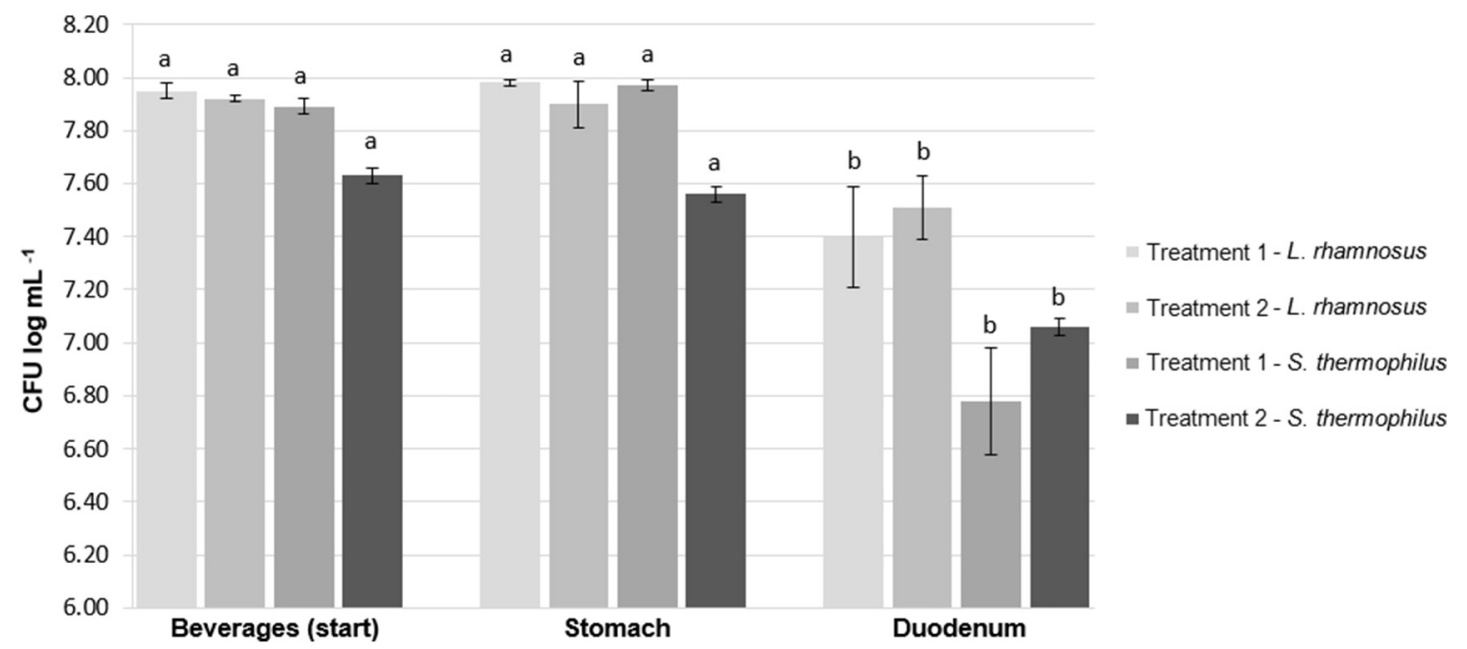

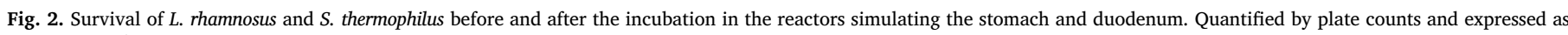

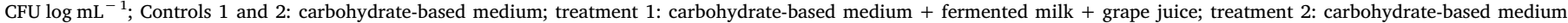

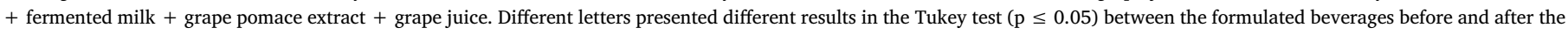
passage through the reactors simulating the stomach and the duodenum.

disease and cancer (Galleano et al., 2012; Prasain, Carlson, \& Wyss, 2010).

3.2. The effect of grape-flavored probiotic fermented beverages made of goat milk with or without added grape pomace on gut microbiota in a Simulator of Human Intestinal Microbial Ecosystem (SHIME ${ }^{\circledR}$ )

3.2.1. Survival of L. rhamnosus and $S$. thermophilus under simulated stomach and duodenum conditions in the SHIME ${ }^{\circledR}$

Fig. 2 shows the survival of L. rhamnosus and $S$. thermophilus in formulations 1 and 2 under the simulated conditions of the stomach and duodenum in the SHIME ${ }^{\circledR}$. The passage of formulations 1 and 2 through the stomach-simulating reactor was not found to affect the survival ( $p>0.05$ ) of L. rhamnosus and S. thermophilus. According to Heller (2001), the presence of foods and food ingredients such as dietary fibers (Sendra, Sayas-Barberá, Fernández-López, \& Pérez-Alvarez, 2016) may have a protective effect on the viability of the microorganisms during their passage through the stomach. Besides, goat milk can be considered a great option for the incorporation of probiotic strains (dos Santos et al., 2016).

During the passage through the duodenum-simulating reactor, a slight ( $\mathrm{p} \leq 0.05$ ) reduction in $L$. rhamnosus survival in both formulations was observed (1: 7.98 to $7.40 \log \mathrm{CFU} \mathrm{mL}{ }^{-1} ; 2: 7.90$ to $7.51 \log \mathrm{CFU} \mathrm{mL}{ }^{-1}$ ). This behavior is typical of probiotic strains, which are able to resist to the acidic $\mathrm{pH}$ of the stomach and the stress conditions of the duodenum (Blanquet-Diot et al., 2012). According to Hill et al. (2014), probiotic products should ideally contain $10^{9} \mathrm{CFU}$ of the probiotic strain per portion of food in order to obtain a reasonable expectation of benefits to the host's wellbeing. Tuo et al. (2013) described that strains of L. rhamnosus were capable of surviving gastrointestinal conditions and adhering to Caco- 2 cells. Other studies have reported that the strain L. rhamnosus GR-1 survived to stomach conditions and to the presence of bile salts, and was capable of colonizing the human intestine for several weeks; the strain was also capable of reducing urinary tract infections and restoring urogenital microbiota (Cadieux et al., 2002; Reid et al., 2001; Reid \& Bruce, 2003).

$S$. thermophilus is a strain that is commonly used as a starter culture in the production of fermented milks, such as yogurts and cheeses. This microorganism is responsible for accelerating of the fermentation process through the production of lactic acid and secondary metabolites, which contribute to the sensory properties of fermented products (Uriot et al., 2016).

A significant decrease in $S$. thermophilus populations was expected after passage through the simulated duodenum conditions. However, a small ( $\mathrm{p} \leq 0.05$ ) decrease in the survival of this microorganism was observed for both beverages (1: 7.89 to $6.78 \log \mathrm{CFU} \mathrm{mL}{ }^{-1} ; 2: 7.63$ to $7.07 \log \mathrm{CFU} \mathrm{mL}{ }^{-1}$ ). Uriot et al. (2016) observed an intense decrease in the population of four $S$. thermophilus strains tested in isolation after their passages through the simulated duodenum conditions in a dynamic in vitro model (TIM). This decrease was likely due to the presence of bile salts, which affect phospholipids and proteins of the cellular membrane (Fang, Lai, \& Chou, 2013). The results obtained in this study showed that the tested food matrices protected both microorganisms present, which were a probiotic and a starter culture.

\subsubsection{Microbiological analysis of the SHIME ${ }^{\circledR}$ samples}

Table 4 presents the impact of treatments 1 and 2 on the populations of Lactobacillus spp., Bifidobacterium spp., Clostridium spp., total anaerobes and total coliform in the reactors simulating the three portions of the colon (AC, DC, and TC).

In the reactor simulating the $\mathrm{AC}$, all bacterial populations analyzed reduced ( $\mathrm{p} \leq 0.05$ ) during treatment 1 (fermented milk + grape juice). Meanwhile, in the reactor that simulating the TC, there were reductions ( $\mathrm{p} \leq 0.05$ ) in the Clostridium spp. and total anaerobes population. In the reactor simulating the $\mathrm{DC}$, there was an increase $(\mathrm{p} \leq 0.05)$ in Lactobacillus spp. and Bifidobacterium spp. populations and a decrease ( $\mathrm{p} \leq 0.05$ ) in total anaerobes microorganisms.

In treatment 2 (fermented milk + grape pomace extract + grape juice), an increase ( $\mathrm{p} \leq 0.05$ ) in Lactobacillus spp. and Clostridium spp. were found in the reactor simulating the AC. An increase ( $\mathrm{p} \leq 0.05)$ in the Lactobacillus spp. population was observed only in the reactor simulating the TC. Increases $(\mathrm{p} \leq 0.05)$ in Lactobacillus spp. and Bifidobacterium spp. populations were observed in the reactor simulating the DC.

Recent studies suggest that foods rich in phenolic compounds may influence the gut microbiota composition and activity by stimulating or inhibiting specific bacterial groups (Boto-Ordóñez et al., 2014; Espley et al., 2014; Faria, Fernandes, Norberto, Mateus, \& Calhau, 2014; Tabasco et al., 2011). In addition, when present in the colon, these compounds may be metabolized by the resident microbiota producing biologically active metabolites (Van Duynhoven et al., 2011). SánchezPatán et al. (2015) observed decreases in Lactobacillus spp., Bifidobacterium spp., and Clostridium leptum populations after $48 \mathrm{~h}$ of incubation with grape seed extract in the SHIME ${ }^{\circledR}$ model. Barroso et al. (2014) also reported decreases ( $\mathrm{p} \leq 0.05$ ) in Lactobacillus spp. and Bifidobacterium spp. populations after one week of treatment with red 
Table 4

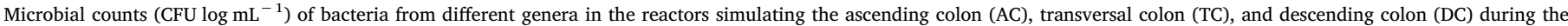
experimental period.

\begin{tabular}{|c|c|c|c|c|c|c|c|}
\hline Genus & Experimental Period & $\mathrm{AC}$ & $\mathrm{t}(\mathrm{p})$ & TC & $\mathrm{t}(\mathrm{p})$ & DC & $\mathrm{t}(\mathrm{p})$ \\
\hline \multirow[t]{4}{*}{ Lactobacillus spp. } & Control 1 & $8.54 \pm 0.03$ & \multirow[t]{2}{*}{$4.76(0.04)$} & $7.84 \pm 0.02$ & \multirow[t]{2}{*}{$-1.15(0.37)$} & $7.30 \pm 0.15$ & \multirow[t]{2}{*}{$-6.79(0.02)$} \\
\hline & Treatment 1 & $7.77 \pm 0.26$ & & $7.92 \pm 0.10$ & & $7.81 \pm 0.02$ & \\
\hline & Control 2 & $8.23 \pm 0.28$ & \multirow[t]{2}{*}{$-6.81(0.02)$} & $7.57 \pm 0.05$ & \multirow[t]{2}{*}{$-14.26(<0.01)$} & $7.08 \pm 0.03$ & \multirow[t]{2}{*}{$-15.16(<0.01)$} \\
\hline & Treatment 2 & $8.45 \pm 0.22$ & & $8.02 \pm 0.10$ & & $7.78 \pm 0.05$ & \\
\hline \multirow[t]{4}{*}{ Bifidobacterium spp. } & Control 1 & $8.10 \pm 0.03$ & \multirow[t]{2}{*}{$15.59(<0.01)$} & $7.63 \pm 0.16$ & \multirow[t]{2}{*}{$0.22(0.85)$} & $7.16 \pm 0.05$ & \multirow[t]{2}{*}{$-14.24(<0.01)$} \\
\hline & Treatment 1 & $7.92 \pm 0.01$ & & $7.59 \pm 0.12$ & & $7.75 \pm 0.03$ & \\
\hline & Control 2 & $8.18 \pm 0.13$ & \multirow[t]{2}{*}{$-2.81(0.10)$} & $7.39 \pm 0.21$ & \multirow[t]{2}{*}{$-3.10(0.09)$} & $6.96 \pm 0.12$ & \multirow[t]{2}{*}{$-8.73(0.01)$} \\
\hline & Treatment 2 & $8.31 \pm 0.21$ & & $7.90 \pm 0.07$ & & $7.71 \pm 0.03$ & \\
\hline \multirow[t]{4}{*}{ Clostridium spp. } & Control 1 & $8.69 \pm 0.09$ & \multirow[t]{2}{*}{$20.04(<0.01)$} & $8.23 \pm 0.01$ & \multirow[t]{2}{*}{$60.84(<0.01)$} & $8.24 \pm 0.29$ & \multirow[t]{2}{*}{$2.29(0.15)$} \\
\hline & Treatment 1 & $8.15 \pm 0.05$ & & $7.89 \pm 0.02$ & & $7.80 \pm 0.03$ & \\
\hline & Control 2 & $8.37 \pm 0.05$ & \multirow[t]{2}{*}{$-5.59(0.03)$} & $7.94 \pm 0.33$ & \multirow[t]{2}{*}{$-0.25(0.83)$} & $7.49 \pm 0.41$ & \multirow[t]{2}{*}{$-0.21(0.85)$} \\
\hline & Treatment 2 & $8.50 \pm 0.09$ & & $8.00 \pm 0.12$ & & $7.54 \pm 0.02$ & \\
\hline \multirow[t]{4}{*}{ Total anaerobes } & Control 1 & $8.94 \pm 0.03$ & \multirow[t]{2}{*}{$13.82(0.01)$} & $8.47 \pm 0.06$ & \multirow[t]{2}{*}{$13.25(0.01)$} & $8.34 \pm 0.20$ & \multirow[t]{2}{*}{$5.11(0.04)$} \\
\hline & Treatment 1 & $7.98 \pm 0.15$ & & $7.83 \pm 0.03$ & & $7.80 \pm 0.02$ & \\
\hline & Control 2 & $8.94 \pm 0.36$ & \multirow[t]{2}{*}{$0.74(0.53)$} & $8.08 \pm 0.43$ & \multirow[t]{2}{*}{$0.02(0.99)$} & $7.72 \pm 0.25$ & \multirow[t]{2}{*}{$-0.40(0.73)$} \\
\hline & Treatment 2 & $8.70 \pm 0.21$ & & $8.07 \pm 0.15$ & & $7.78 \pm 0.01$ & \\
\hline \multirow[t]{4}{*}{ Total coliforms } & Control 1 & $8.08 \pm 0.07$ & \multirow[t]{2}{*}{$5.57(0.03)$} & $7.65 \pm 0.01$ & \multirow[t]{2}{*}{$4.00(0.06)$} & $7.52 \pm 0.12$ & \multirow[t]{2}{*}{$2.84(0.11)$} \\
\hline & Treatment 1 & $6.22 \pm 0.50$ & & $6.06 \pm 0.70$ & & $6.13 \pm 0.73$ & \\
\hline & Control 2 & $7.86 \pm 0.91$ & \multirow[t]{2}{*}{$1.49(0.27)$} & $7.14 \pm 0.92$ & \multirow[t]{2}{*}{$1.15(0.37)$} & $6.82 \pm 0.66$ & \multirow[t]{2}{*}{$1.30(0.32)$} \\
\hline & Treatment 2 & $6.79 \pm 0.34$ & & $6.25 \pm 0.42$ & & $6.02 \pm 0.41$ & \\
\hline
\end{tabular}

Averages \pm standard deviation $(\mathrm{n}=6)$; Student's $t$-test $(\mathrm{p} \leq 0.05)$

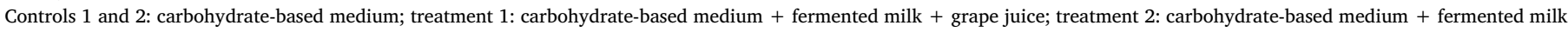
+ grape pomace extract + grape juice.

wine polyphenols in a SHIME ${ }^{\circledR}$ model. Cueva et al. (2013) observed a decrease in the Clostridium histolyticum population after in vitro fermentation of flavonoids from grape seeds in a fermentation model using fecal batch-cultures.

In this study, only treatment 2 had a positive influence on the population of beneficial bacteria present in the colon (Lactobacillus spp. and Bifidobacterium spp.). This effect may be attributed to the higher amounts of fibers, stearic acid, oleic acid, pentadecanoic acid, and phenolic compounds, as well as the antioxidant activity present in this formulation.

DGGE analysis on total bacteria was used to evaluate the qualitative changes that potentially occurred within the microbial community during the treatment periods (Fig. 3). The data is presented as a cluster analysis conducted on a composite dataset of the one gel using the unweighted pair group with mathematical averages (UPGMA) and distance matrices of each DGGE gel based on the Pearson correlation similarity coefficients.

The cluster analysis in all reactors simulating the different regions of the colon resulted in two distinct clusters (cluster 1: control 1; cluster 2: treatment 1, control 2 and treatment 2). The treatment 1 altered the total bacteria population during control period 1 . However, treatment 1 and control 2 showed high similarity in all reactors simulating the

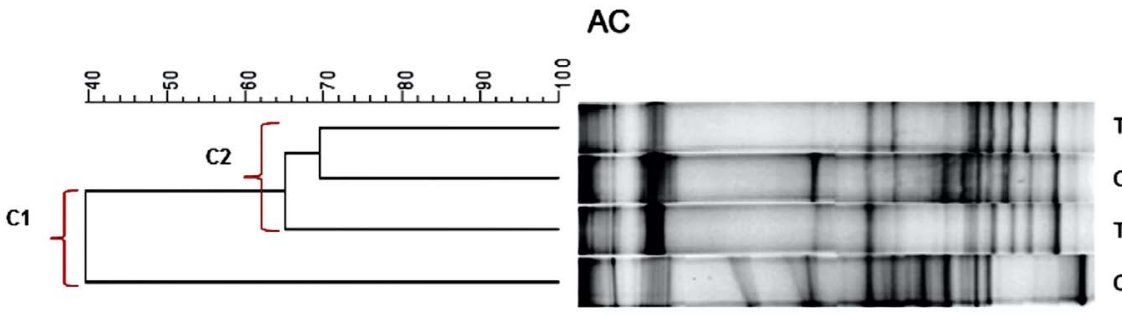

TC

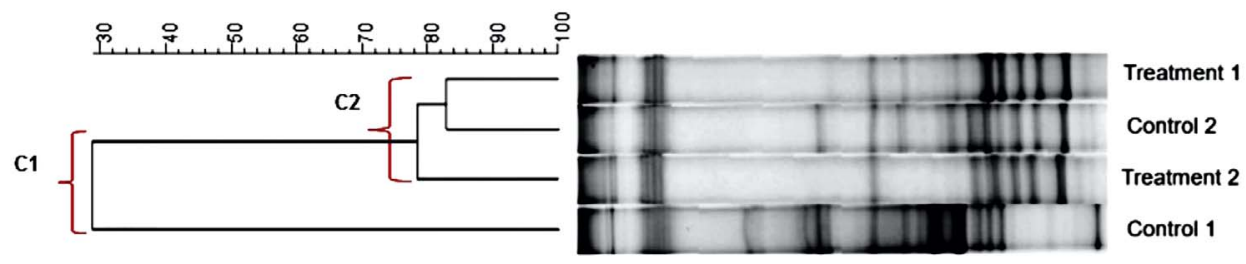

DC

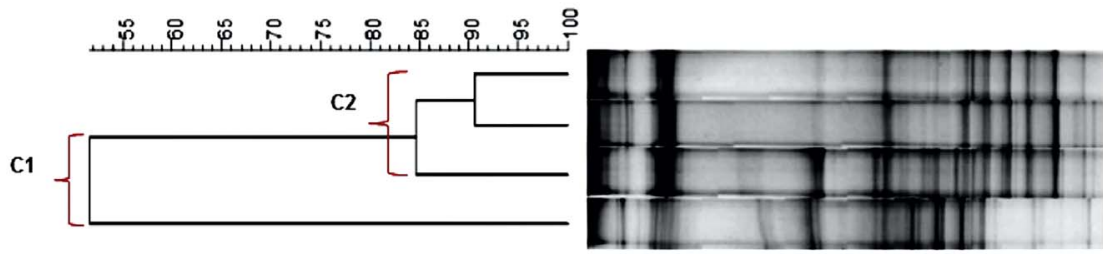

Treatment 1

Control 2

Treatment 2 Control 1
Treatment 1

Treatment 2
Fig. 3. Denaturing gradient gel electrophoresis (DGGE) of the total bacteria profiles in the reactors simulating the ascending colon (AC), transversal colon (TC), and descending colon (DC) during the experimental period. Controls 1 and 2: carbohydrate-based medium; treatment 1: carbohydrate-based medium + fermented milk + grape juice; treatment 2: carbohydrate-based medium + fermented milk + grape pomace extract + grape juice. 


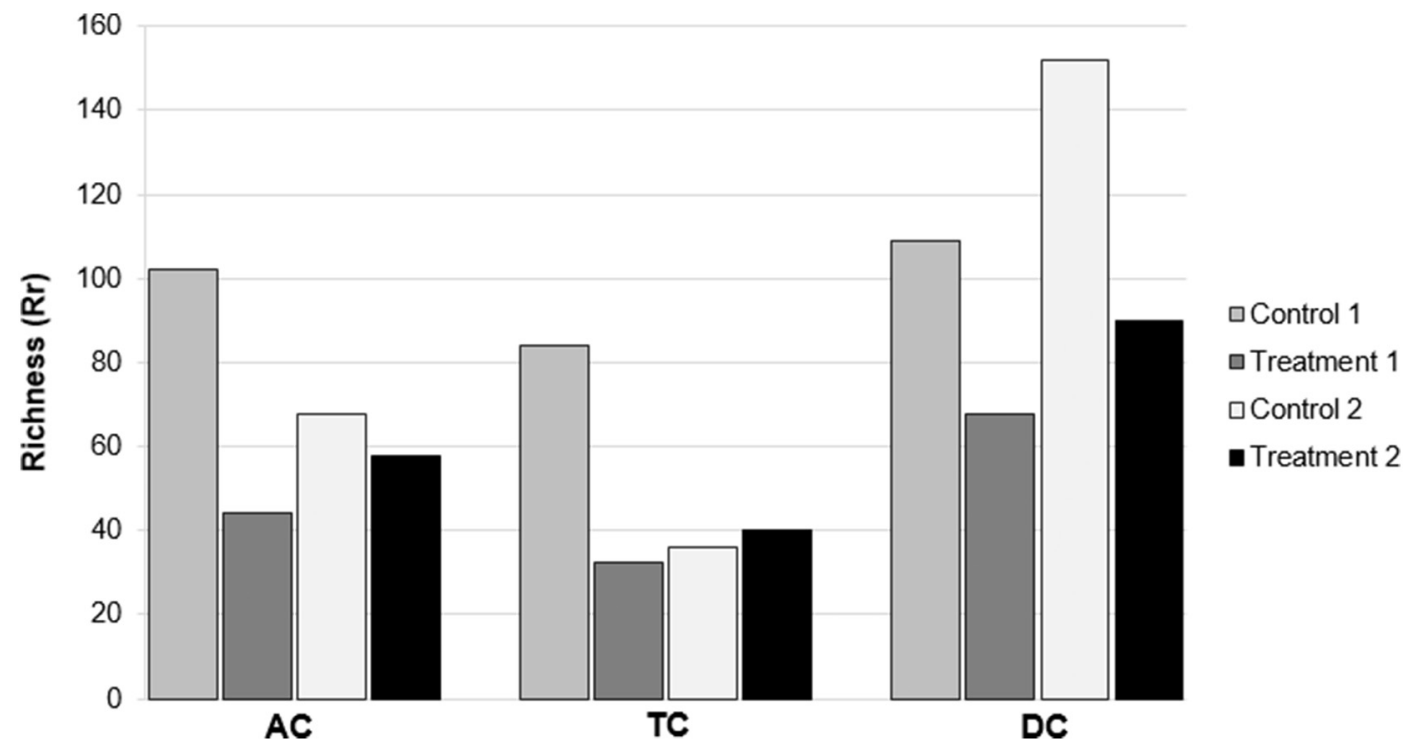

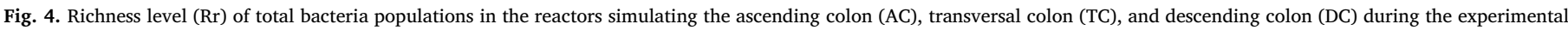

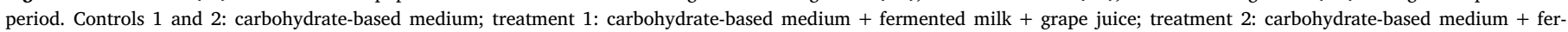
mented milk + grape pomace extract + grape juice.

different regions of the colon (AC, DC, and TC). The long-term administrations of the treatments induced a change toward the development of a new community structure.

The effect of the treatments on the structure of the total microbial community in the SHIME ${ }^{\circledR}$ system was investigated based on the interpretation of general bacterial DGGE fingerprints, according to a Marzorati et al. (2008). Fig. 4 shows the level of richness (Rr) of the total bacteria population in the reactors simulating the AC, TC, and DC during the experimental period. All the colon reactors presented $\mathrm{Rr}$ values over 30. According to Marzorati et al. (2008), richness values below 10 represent environments of restricted colonization. However, values between 10 and 30 correspond to a microbial community of medium richness. Values above 30 represent a microbial community of great diversity typical of a very inhabitable environment. According to this classification, it is possible to state that all of the colon simulation reactors used herein presented an environment of high richness ( $\mathrm{Rr}>30)$. Ecological interpretation of general bacterial DGGE fingerprints (Marzorati et al., 2008) showed a reduction in $\mathrm{Rr}$ during the treatment periods 1 and 2 in relation to respective control periods, except between the control period 2 and treatment 2 in the reactor simulating the TC. Kemperman et al. (2013) suggest that the polyphenols in red wine extract may have an impact on the composition of total bacteria. These authors showed that the polyphenols in red wine stimulated the growth of some bacterial genera, such as Klebsiella, Alistipes, Cloacibacillus, Victivallis, and Akkermansia. However, populations of other genera decreased, including Bifidobacteria, B. coccoides, Anaeroglobus, Subdoligranulum and Bacteroides. Moreover, these authors also reported that some specific groups of bacteria may be vulnerable to the presence of these compounds, while other groups are not affected or even stimulated, thus rendering them more frequent in the microbial community after the consumption of red wine polyphenols.

In terms of the structure and functionality of the bacterial communities, all of the reactors simulating the colon (AC, TC, and DC) presented values close to $45 \%$ on the Pareto-Lorenz curve (Fig. 5). According to Marzorati et al. (2008), points close to a Pareto-Lorenz curve of $45 \%$ reflect low uniformity of the microbial community, with most species being dominant. This configuration is commonly described as a well-balanced population of bacteria, with great potential to handle environmental alterations while remaining functional. Similar results were obtained by Sivieri et al. (2014) and Possemiers et al. (2010).
3.2.3. Ammonium $\left(\mathrm{NH}_{4}{ }^{+}\right)$and short- and branched-chain fatty acids (SCFAs and BCFAs) analysis

$\mathrm{NH}_{4}{ }^{+}$corresponds to one of the metabolites resulting from protein fermentation by intestinal bacteria. The fermented beverages formulated herein presented approximately $2.6 \%$ protein content. Nonetheless, a reduction $(\mathrm{p} \leq 0.05)$ in the production of $\mathrm{NH}_{4}^{+}$was observed in all the reactors simulating the regions of the colon (AC, TC, and DC) during treatment periods 1 and 2 (Table 5). Most $\mathrm{NH}_{4}{ }^{+}$are absorbed in the colon, metabolized into urea in the liver, and excreted in urine. $\mathrm{NH}_{4}{ }^{+}$can alter the morphology of intestinal cells and promote carcinogenesis in the colon (Scott et al., 2013).

SCFAs are produced by the microbiota as a result of the fermentation of compounds that are not digestible by the gastrointestinal tract. These acids possess $<6$ atoms of carbon and can have linear or branched chains. They are produced by the fermentation of carbohydrates ingested from food. However, the breaking-down of proteins can also result in branched chain fatty acids (BCFAs), such as isobutyrate, isovalerate, and 2-methyl butyrate, thus contributing to $5 \%$ of total SCFA production (Ríos-Covián et al., 2016).

In this study, increases ( $\mathrm{p} \leq 0.05)$ in acetic acid and butyric acid were observed in all reactors simulating the different regions of the colon during treatment periods 1 and 2 (Table 6). However, propionic acid decreased $(\mathrm{p} \leq 0.05)$ during treatment period 1 , and a significant increase was observed during treatment period 2 in all colon reactors.

A substantial increase in SCFAs was observed during the treatment period 2. This increase may be attributed to the fibers present in grape pomace extract, since they are a source of carbon and can be metabolized by intestinal bacteria of the genera Lactobacillus spp. and Bifidobacterium spp. (Fernández et al., 2016). In this context, the treatment 2 showed an increase $(\mathrm{p} \leq 0.05)$ of Lactobacillus spp. and Bifidobacterium spp. (Table 4). Similar results were observed by Sivieri et al. (2014) in their study of the prebiotic effect of fruit oligosaccharides on gut microbiota using a SHIME $^{\circledR}$ model.

Some health benefits are attributed to SCFAs. They include decreases in luminal pH (which can inhibit pathogenic microorganisms and increase nutrient absorption), increases in mucin production (which modifies the adhesion of bacteria to intestinal cells) and a stimulation of cellular proliferation in the intestinal epithelium (RíosCovián et al., 2016). Acetic acid is the most abundant SCFA in the colon, being responsible for provide energy to cells and induce cholesterol synthesis (Hijova \& Chmelarova, 2007). Butyric acid is the most 

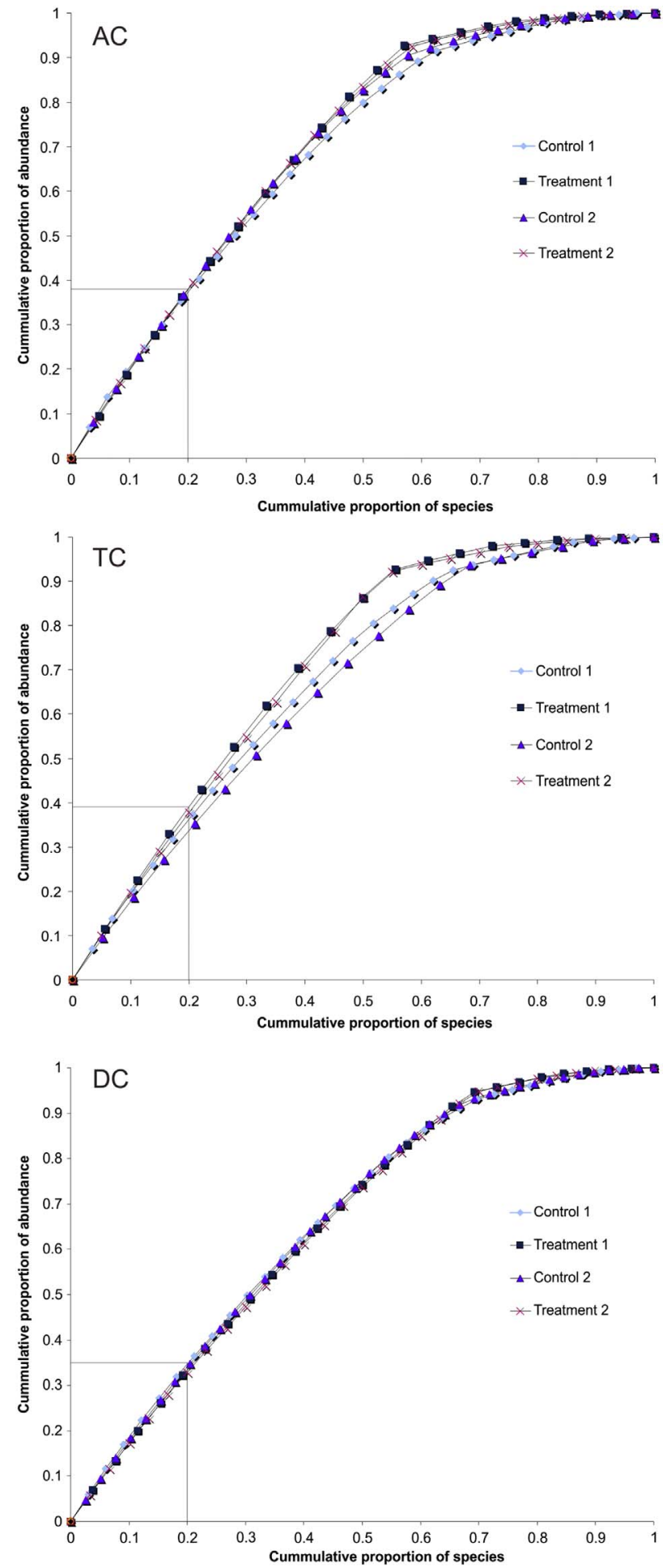

Fig. 5. Pareto-Lorenz curve of the reactors simulating the ascending colon (AC), transversal colon (TC), and descending colon (DC) during the experimental period. Controls 1 and 2: carbohydrate-based medium; treatment 1: carbohydrate-based medium + fermented milk + grape juice; treatment 2 : carbohydrate-based medium + fermented milk + grape pomace extract + grape juice.

important metabolite produced in the colon; it is the main source of energy for the colonocytes, stimulates visceral blood flow, contributes to sodium and water absorption, besides presenting anti-inflammatory and anti-carcinogenic properties (Montalto, D'onofrio, Gallo, Cazzato, \& Gasbarrini, 2009; Mortensen \& Clausen, 1996). Propionic acid is responsible for reducing lipogenesis and inhibiting the serum cholesterol synthesis (Hijova \& Chmelarova, 2007; Hosseini, Grootaert,
Verstraete, \& Van de Wiele, 2011).

The production of SCFAs observed in this study may have also been influenced by the degradation of phenolic compounds present in the grape pomace extract and grape juice. According to Tuohy, Conterno, Gasperotti, and Viola (2012), gut microbiota can hydrolyze complex phenolic compounds in smaller compounds, thus producing SCFAs. Schneider, Schwiertz, Collins, and Blaut (1999) and Schoefer, Mohan, Schwiertz, et al. (2003) observed that some colon bacteria isolated from human feces used flavonoids as an energy source, thus releasing butyric acid. Bravo, Abia, Eastwood, and Saura-Calixtol (1994) observed that tannic acid and catechins were degraded by the gut microbiota during the fermentation process, producing butyric acid in an in vitro fermentation model inoculated with rat feces.

There was no difference ( $p>0.05$ ) in BCFAs levels between the control periods and respective treatment periods. Studies suggest that BCFAs may have a regulatory effect and may increase anti-inflammatory cytokine expression (Ran-Ressler et al., 2014). Other studies have reported that BCFAs induce apoptosis in breast cancer cells and inhibit the growth of tumors in animal models (Wongtangtintharn, Oku, Iwasaki, \& Toda, 2004; Yang et al., 2000).

\subsubsection{Antioxidant capacity of SHIME ${ }^{\circledR}$ samples}

Fig. 6 presents the antioxidant capacity of the samples collected from the reactors simulating the three regions of the colon (AC, TC, and DC) during both treatment periods. All of the reactors exhibited higher ( $\mathrm{p} \leq 0.05$ ) antioxidant capacity in treatment periods 1 and 2 when compared to the respective control periods. Duque, Monteiro, Adorno, Sakamoto, and Sivieri (2016) analyzed the effect of orange juice consumption on gut microbiota using a SHIME ${ }^{\circledR}$ model. The authors observed the same behavior in the antioxidant capacity during the treatment and control periods.

Studies suggest that long term consumption of fruits and vegetables plays a central role in the prevention at many chronic diseases (Pandey \& Rizvi, 2009; Sun, Chu, Wu, \& Liu, 2002). In the gastrointestinal tract, these health-protective effects are partially attributed to their antioxidant properties (Halliwell, Zhao, \& Whiteman, 2000), which have been associated with their high phytochemical (phenolic compounds) and antioxidant dietary fiber contents. The result obtained in this study suggests that most of the phenolic compounds present both in grape pomace extract and in grape juice were available in the reactors simulating the colon for fermentation by intestinal microbiota.

\subsection{Principal component analysis (PCA)}

A PCA was performed throughout the experimental period in the SHIME $^{\circledR}$, and the components explained $83.78 \%$ of the total variation of results (Fig. 7A). Principal component 1 explained 50.05\% of data analyzed and was described by the production of acetic acid and butyric acid, antioxidant capacity and Lactobacillus spp. and Bifidobacterium spp. populations.

Principal component 2 explained $33.73 \%$ of the total variation of results and was described by Clostridium populations, total coliforms, propionic acid, and $\mathrm{NH}_{4}^{+}$production.

Fig. 7B shows that the control and treatment periods were grouped in two distinct clusters. The treatment periods were described by increases in acetic acid and butyric acid production, antioxidant activity, and Lactobacillus spp. and Bifidobacterium spp. populations. Meanwhile, the control periods were described by the increase in Clostridium spp. populations and in the total coliforms, as well as by the production of propionic acid and $\mathrm{NH}_{4}{ }^{+}$ions.

These results suggest that both treatment periods had a positive effect on gut microbiota, since they allowed for positive metabolic changes in the different regions simulating the colon (AC, TC, and DC). 
Table 5

Concentration of $\mathrm{NH}_{4}{ }^{+}$(mmol/L) in the reactors simulating the ascending colon (AC), transversal colon (TC), and descending colon (DC) during the experimental period.

\begin{tabular}{|c|c|c|c|c|c|c|}
\hline Experimental period & $\mathrm{AC}$ & $\mathrm{t}(\mathrm{p})$ & TC & $\mathrm{t}(\mathrm{p})$ & DC & $\mathrm{t}(\mathrm{p})$ \\
\hline Control 1 & $20.71 \pm 0.23$ & & $21.23 \pm 0.06$ & & $17.07 \pm 0.06$ & \\
\hline Treatment 1 & $12.12 \pm 0.12$ & $97.23(<0.01)$ & $9.41 \pm 0.47$ & $39.60(<0.01)$ & $9.33 \pm 0.31$ & $36.35(<0.01)$ \\
\hline Control 2 & $12.88 \pm 0.03$ & & $16.11 \pm 0.09$ & & $20.32 \pm 0.09$ & \\
\hline Treatment 2 & $3.70 \pm 0.04$ & $322.21(<0.01)$ & $3.59 \pm 0.05$ & $233.45(<0.01)$ & $8.87 \pm 0.06$ & $617.30(<0.01)$ \\
\hline
\end{tabular}

Averages \pm standard deviation $(\mathrm{n}=3$ ); Student's $t$-test $(\mathrm{p} \leq 0.05)$.

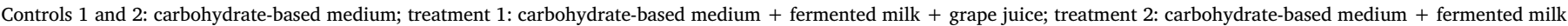

+ grape pomace extract + grape juice.

Table 6

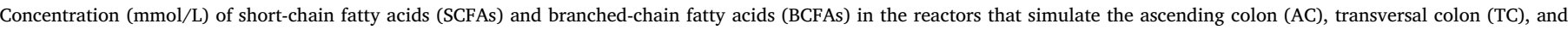
descending colon (DC) during the experimental period.

\begin{tabular}{|c|c|c|c|c|c|c|c|}
\hline \multicolumn{2}{|c|}{ Experimental period } & \multirow{3}{*}{$\begin{array}{l}\mathrm{AC} \\
69.27 \pm 5.82 \\
112.75 \pm 10.94\end{array}$} & \multirow{2}{*}{$\frac{t(p)}{-4.50(0.05)}$} & \multirow{3}{*}{$\begin{array}{l}\text { TC } \\
77.80 \pm 6.03 \\
158.17 \pm 13.33\end{array}$} & \multirow{2}{*}{$\frac{t(p)}{-7.19(0.02)}$} & \multirow{3}{*}{$\begin{array}{l}\text { DC } \\
73.73 \pm 5.72 \\
165.75 \pm 8.33\end{array}$} & \multirow{2}{*}{$\frac{t(p)}{-11.39(0.01)}$} \\
\hline Acetic acid & Control 1 & & & & & & \\
\hline & Treatment 1 & & & & & & \\
\hline & Control 2 & $40.16 \pm 0.96$ & $-27.51(<0.01)$ & $48.51 \pm 2.66$ & $-13.99(0.01)$ & $42.55 \pm 3.34$ & $-53.63(<0.01)$ \\
\hline & Treatment 2 & $101.62 \pm 2.92$ & & $157.02 \pm 10.78$ & & $168.73 \pm 0.74$ & \\
\hline \multirow[t]{4}{*}{ Propionic acid } & Control 1 & $15.83 \pm 4.16$ & $0.54(0.64)$ & $20.82 \pm 2.62$ & $3.50(0.07)$ & $17.25 \pm 0.45$ & $25.44(<0.01)$ \\
\hline & Treatment 1 & $13.88 \pm 2.10$ & & $12.22 \pm 1.64$ & & $10.20 \pm 0.04$ & \\
\hline & Control 2 & $7.54 \pm 0.86$ & $-4.40(0.05)$ & $6.29 \pm 0.07$ & $-9.32(0.01)$ & $7.11 \pm 1.05$ & $-5.45(0.03)$ \\
\hline & Treatment 2 & $16.12 \pm 2.53$ & & $15.36 \pm 1.62$ & & $10.54 \pm 0.04$ & \\
\hline \multirow[t]{4}{*}{ Butyric acid } & Control 1 & $12.85 \pm 4.91$ & $-7.82(0.02)$ & $7.63 \pm 1.50$ & $-5.00(0.04)$ & $2.84 \pm 0.03$ & $-33.81(<0.01)$ \\
\hline & Treatment 1 & $24.38 \pm 2.35$ & & $33.79 \pm 7.57$ & & $30.36 \pm 1.38$ & \\
\hline & Control 2 & $10.72 \pm 1.51$ & $-5.50(0.03)$ & $13.72 \pm 0.66$ & $-23.29(<0.01)$ & $9.85 \pm 0.91$ & $-7.11(0.02)$ \\
\hline & Treatment 2 & $45.30 \pm 9.39$ & & $36.85 \pm 2.38$ & & $28.95 \pm 5.56$ & \\
\hline \multirow[t]{4}{*}{ Total BCFAs } & Control 1 & $2.57 \pm 0.20$ & $0.48(0.67)$ & $2.39 \pm 0.10$ & $0.13(0.91)$ & $2.66 \pm 0.41$ & $1.15(0.33)$ \\
\hline & Treatment 1 & $2.49 \pm 0.24$ & & $2.38 \pm 0.30$ & & $2.40 \pm 0.19$ & \\
\hline & Control 2 & $2.31 \pm 0.14$ & $-0.55(0.62)$ & $2.30 \pm 0.15$ & $-0.68(0.55)$ & $2.71 \pm 0.54$ & $2.00(0.14)$ \\
\hline & Treatment 2 & $2.39 \pm 0.17$ & & $2.39 \pm 0.23$ & & $2.17 \pm 0.15$ & \\
\hline
\end{tabular}

Averages \pm standard deviation $(\mathrm{n}=3$ ); Student's $t$-test $(\mathrm{p} \leq 0.05)$.

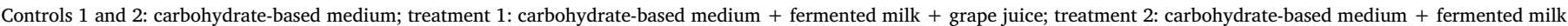
+ grape pomace extract + grape juice.

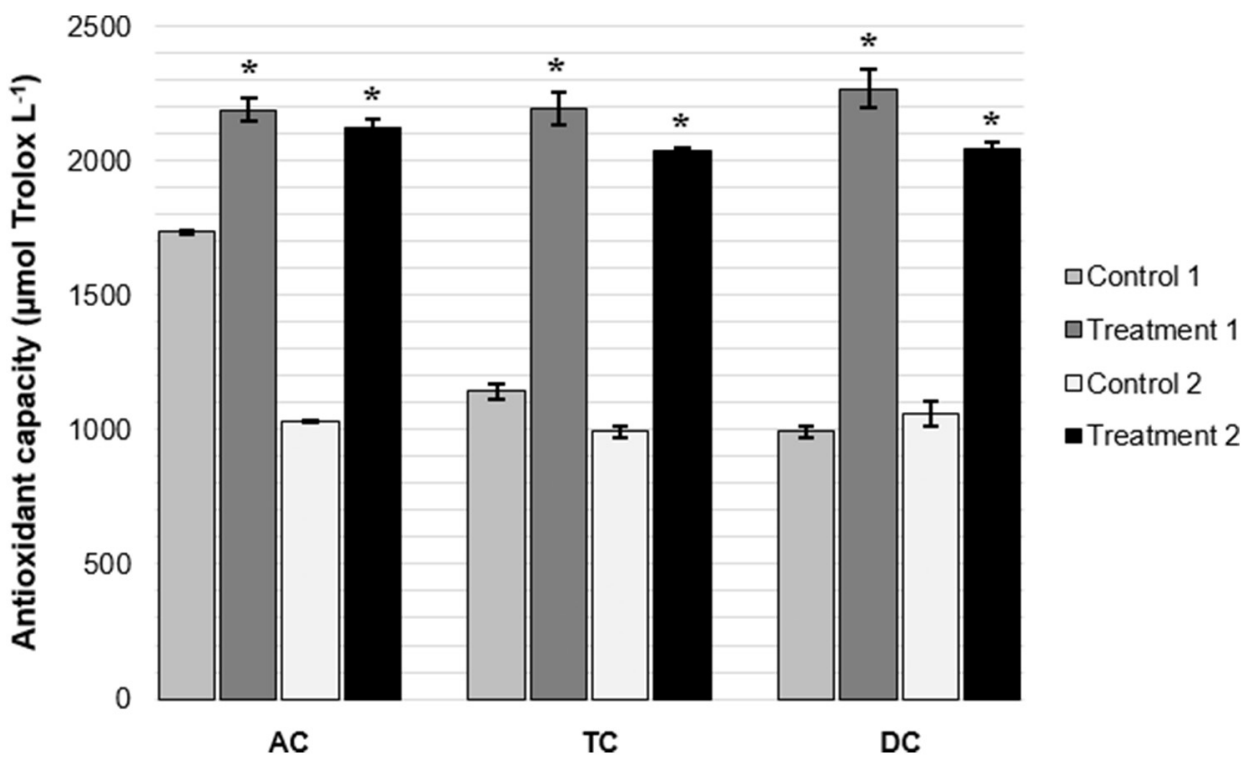

Fig. 6. Antioxidant capacity of the reactors simulating the ascending colon (AC), transversal colon (TC), and descending colon (DC) during the experimental period. Controls 1 and 2: carbohydrate-based medium; treatment 1: carbohydrate-based medium + fermented milk + grape juice; treatment 2 : carbohydrate-based medium + fermented milk + grape pomace extract + grape juice. Averages with * have significantly different values on Student's $t$-test $(\mathrm{p} \leq 0.05)$ in control period 1 versus treatment period 1 and in control period 2 versus treatment 2 in the different reactors.

\section{Conclusion}

Foods comprised of different types of bioactive compounds may be considered "multifunctional foods." The results observed in this study demonstrated that probiotic fermented beverages made of goat milk and grape juice, with or without grape pomace extract, had high amounts of dietary fiber, oleic acid and phenolic compounds content, which are considered biologically active. The beverages had a protective effect on L. rhamnosus and $S$. thermophilus microorganisms during their passage through the gastrointestinal tract, and were also found to have a positive effect on gut microbiota. They altered the composition of the microbial structure and improved bacterial metabolism in the different regions simulating the colon. In summary, the beverages formulated in this study can be considered a multifunctional food and offer a new perspective for the production of foods with potential positive effects on human health. 

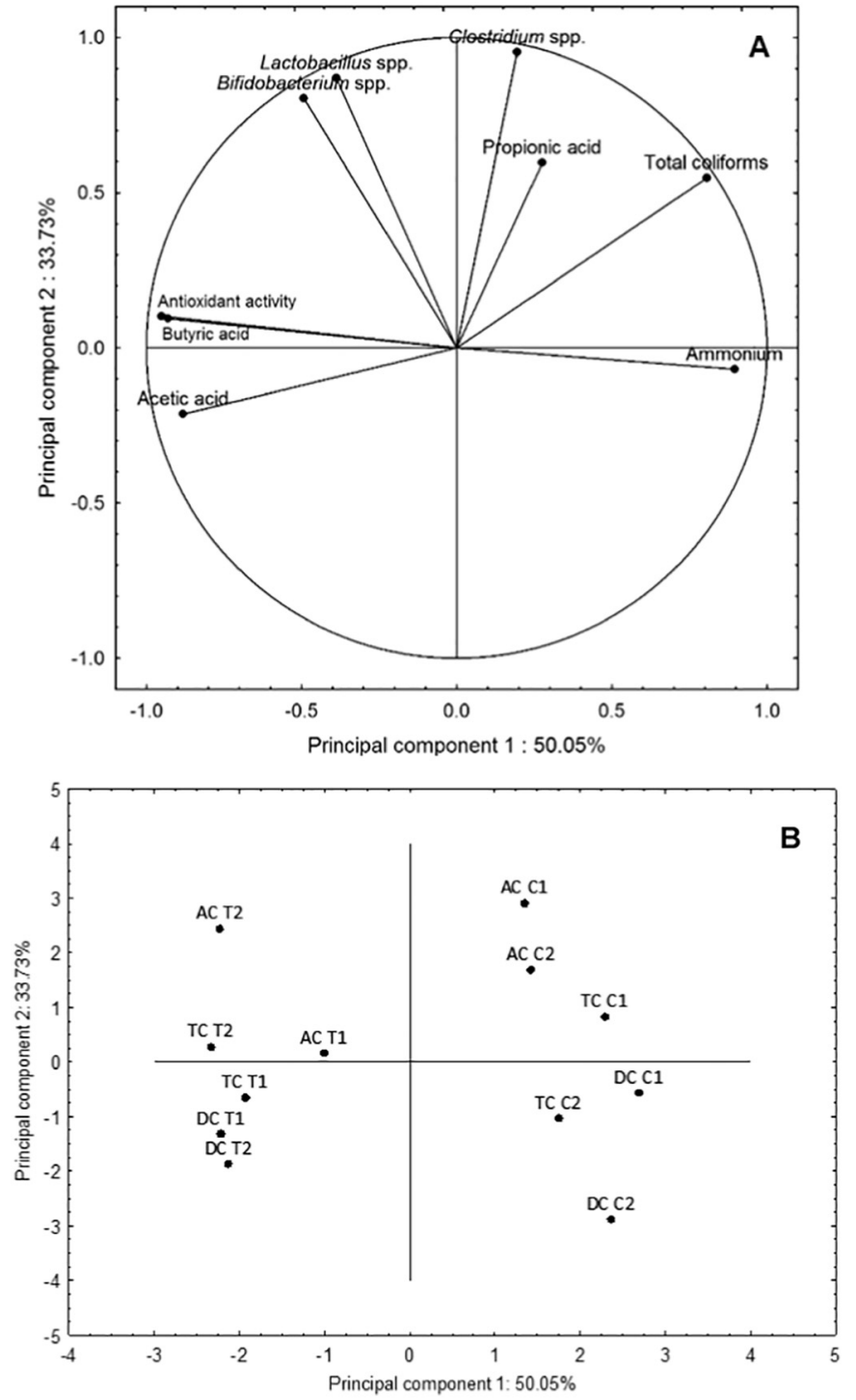

Fig. 7. Principal component analysis (A: variable projection; B: sample projection) of the in vitro SHIME ${ }^{\circledR}$ model. AC: ascending colon; TC: transversal colon; DC: descending colon; C1: control 1 (carbohydrate-based medium); C2: control 2 (carbohydrate-based medium); T1: treatment 1 (carbohydrate-based medium + fermented milk + grape juice); T2: treatment 2 (carbohydrate-based medium + fermented milk + grape pomace extract + grape juice).

\section{Acknowledgments}

This work was supported by grants from FAPESP (São Paulo Research Foundation - process number 2015/00460-7) and EMBRAPA (project number 03.14.13.003.00.00).

\section{References}

Adorno, M. A. T., Hirasawa, J. S., \& Varesche, M. B. A. (2014). Development and validation of two methods to quantify volatile acids (C2-C6) by gc/fid: Headspace (automatic and manual) and liquid-liquid extraction (LLE). American Journal of Analytical Chemistry, 5(7), 406-414.

Anderson, J. W., Baird, P., Davis, R. H., Ferreri, S., Knudtson, M., Koraym, A., ... Williams, C. L. (2009). Health benefits of dietary fiber. Nutrition Reviews, 67(4), 188-205.

Antolovich, M., Prenzler, P., Robards, K., \& Ryan, D. (2000). Sample preparation in the determination of phenolic compounds in fruits. Analyst, 125(5), 989-1009.

AOAC (2005). Official methods of analysis of the Association of Official Analytical Chemists. Gaithersburg, MD, USA: AOAC International.

AOAC (2012). Official methods of analysis of the Association of Official Analytical Chemists (19th ed.). Gaithersburg, MD, USA: AOAC International.

Barroso, E., Van De Wiele, T., Jiménez-Girón, A., Muñoz-González, I., Martín-Alvarez, P. J., Moreno-Arribas, M. V., ... Requena, T. (2014). Lactobacillus plantarum IFPL935 impacts colonic metabolism in a simulator of the human gut microbiota during feeding with red wine polyphenols. Applied Microbiology and Biotechnology, 98(15), 6805-6815.

Besler, H. T., \& Grimble, R. F. (1995). Comparison of the modulatory influence of maize and olive oils and butter on metabolic responses to endotoxin in rats. Clinical Science, 88(1), 59-66.

Bianchi, F., Rossi, E. A., Sakamoto, I. K., Adorno, M. A. T., Van de Wiele, T., \& Sivieri, K. (2014). Beneficial effects of fermented vegetal beverages on human gastrointestinal microbial ecosystem in a simulator. Food Research International, 64, 43-52.

Blanquet-Diot, S., Denis, S., Chalancon, S., Chaira, F., Cardot, J. M., \& Alric, M. (2012) Use of artificial digestive systems to investigate the biopharmaceutical factors influencing the survival of probiotic yeast during gastrointestinal transit in humans. Pharmaceutical Research, 29(6), 1444-1453.

Boto-Ordóñez, M., Rothwell, J. A., Andres-Lacueva, C., Manach, C., Scalbert, A., \& UrpiSarda, M. (2014). Prediction of the wine polyphenol metabolic space: An application of the phenol-explorer database. Molecular Nutrition \& Food Research, 58(3), 466-477.

Bravo, L., Abia, R., Eastwood, M. A., \& Saura-Calixtol, F. (1994). Degradation of polyphenols (catechin and tannic acid) in the rat intestinal tract. Effect on colonic fermentation and faecal output. British Journal of Nutrition, 71(6), 933-946.

Cadieux, P., Burton, J., Gardiner, G., Braunstein, I., Bruce, A. W., Kang, C. Y., \& Reid, G. (2002). Lactobacillus strains and vaginal ecology. JAMA, 287(15), 1940-1941.

de Campos, L. M. A. S., Leimann, F. V., Pedrosa, R. C., \& Ferreira, S. R. S. (2008). Free radical scavenging of grape pomace extracts from Cabernet sauvingnon (Vitis vinifera). Bioresource Technology, 99(17), 8413-8420.

Cardarelli, H. R., Buriti, F. C. A., Castro, I. A., \& Saad, S. M. I. (2008). Inulin and oligofructose improve sensory quality and increase the probiotic viable count in potentially synbiotic petit-suisse cheese. LWT - Food Science and Technology, 41(6), 1037-1046.

Cataneo, C. B., Caliari, V., Gonzaga, L. V., Kuskoski, E. M., \& Fett, R. (2008). Atividade antioxidante e conteúdo fenólico do resíduo agroindustrial da produção de vinho. Semina: Ciencias Agrarias, 29(1), 93-102.

Ceballos, L. S., Morales, E. R., de la Torre Adarve, G., Castro, J. D., Martínez, L. P. \& Sampelayo, M. R. S. (2009). Composition of goat and cow milk produced under similar conditions and analyzed by identical methodology. Journal of Food Composition and Analysis, 22(4), 322-329.

Chaikham, P., \& Apichartsrangkoon, A. (2014). Effects of encapsulated Lactobacillus acidophilus along with pasteurized longan juice on the colon microbiota residing in a dynamic simulator of the human intestinal microbial ecosystem. Applied Microbiology and Biotechnology, 98(1), 485-495.

Chouchouli, V., Kalogeropoulos, N., Konteles, S. J., Karvela, E., Makris, D. P., \& Karathanos, V. T. (2013). Fortification of yoghurts with grape (Vitis vinifera) seed extracts. LWT - Food Science and Technology, 53(2), 522-529.

Christie, W. W. (1982). Chromatographic and spectroscopic analysis of lipids: General principles. Lipid Analysis, 25-49.

Cruz-Hernandez, C., Kramer, J. K. G., Kennelly, J. J., Glimm, D. R., Sorensen, B. M., Okine, E. K., ... Weselake, R. J. (2007). Evaluating the conjugated linoleic acid and trans 18:1 isomers in milk fat of dairy cows fed increasing amounts of sunflower oil and a constant level of fish oil. Journal of Dairy Science, 90(8), 3786-3801.

Cueva, C., Sánchez-Patán, F., Monagas, M., Walton, G. E., Gibson, G. R., Martín-Álvarez, P. J., ... Moreno-Arribas, M. V. (2013). In vitro fermentation of grape seed flavan-3-ol fractions by human faecal microbiota: Changes in microbial groups and phenolic metabolites. FEMS Microbiology Ecology, 83(3), 792-805.

Dejonghe, W., Boon, N., Seghers, D., Top, E. M., \& Verstraete, W. (2001). Bioaugmentation of soils by increasing microbial richness: Missing links. Environmental Microbiology, 3(10), 649-657.

Djilas, S., Čanadanović-Brunet, J., \& Ćetković, G. (2009). By-products of fruits processing as a source of phytochemicals. Chemical Industry and Chemical Engineering Quarterly, 15(4), 191-202.

Duque, A. L. R. F., Monteiro, M., Adorno, M. A. T., Sakamoto, I. K., \& Sivieri, K. (2016) An exploratory study on the influence of orange juice on gut microbiota using a dynamic colonic model. Food Research International, 84, 160-169.

Engelen, B., Felske, A., Snaidr, J., Wieshuber, A., Amann, R. I., Ludwig, W., \& Backhaus, H. (1996). Sequence heterogeneities of genes encoding 16S rRNAs in Paenibacillus polymyxa detected by temperature gradient gel electrophoresis. Journal of Bacteriology, 178(19), 5636-5643.

Espley, R. V., Butts, C. A., Laing, W. A., Martell, S., Smith, H., Mcghie, T. K., ... Hellens, R. P. (2014). Dietary flavonoids from modified apple reduce inflammation markers and modulate gut microbiota in mice. The Journal of Nutrition, 147(1), 146-154.

Fang, S. H., Lai, Y. J., \& Chou, C. C. (2013). The susceptibility of Streptococcus thermophilus 14085 to organic acid, simulated gastric juice, bile salt and disinfectant as influenced by cold shock treatment. Food Microbiology, 33(1), 55-60.

Faria, A., Fernandes, I., Norberto, S., Mateus, N., \& Calhau, C. (2014). Interplay between anthocyanins and gut microbiota. Journal of Agricultural and Food Chemistry, 62(29), 6898-6902.

Fernández, J., Redondo-Blanco, S., Gutiérrez-del-Río, I., Miguélez, E. M., Villar, C. J., \& Lombó, F. (2016). Colon microbiota fermentation of dietary prebiotics towards shortchain fatty acids and their roles as anti-inflammatory and antitumour agents: A review. Journal of Functional Foods, 25, 511-522.

Ferrara, L. A., Raimondi, A. S., d'Episcopo, L., Guida, L., Russo, A. D., \& Marotta, T. (2000). Olive oil and reduced need for antihypertensive medications. Archives of Internal Medicine, 160(6), 837-842.

Frumento, D., Santo, A. P. E., Aliakbarian, B., Casazza, A. A., Gallo, M., Converti, A., \& Perego, P. (2013). Development of milk fermented with Lactobacillus acidophilus fortified with Vitis vinifera marc flour. Food Technology and Biotechnology, 51(3), 370-375.

Galleano, M., Calabro, V., Prince, P. D., Litterio, M. C., Piotrkowski, B., Vazquez-Prieto, 
M. A., ... Fraga, C. G. (2012). Flavonoids and metabolic syndrome. Annals of the New York Academy of Sciences, 1259(1), 87-94.

Georgé, S., Brat, P., Alter, P., \& Amiot, M. J. (2005). Rapid determination of polyphenols and vitamin C in plant-derived products. Journal of Agricultural and Food Chemistry, 53(5), 1370-1373.

Gibson, G. R., \& Roberfroid, M. B. (1995). Dietary modulation of the human colonic microbiota: Introducing the concept of prebiotics. The Journal of Nutrition, 125(6), 1401-1412.

Goldin, B. R., Gorbach, S. L., Saxelin, M., Barakat, S., Gualtieri, L., \& Salminen, S. (1992). Survival of Lactobacillus species (strain GG) in human gastrointestinal tract. Digestive Diseases and Sciences, 37(1), 121-128.

Griinari, J. M., Corl, B. A., Lacy, S. H., Chouinard, P. Y., Nurmela, K. V. V., \& Bauman, D. E. (2000). Conjugated linoleic acid is synthesized endogenously in lactating dairy cows by $\Delta 9$-desaturase. The Journal of Nutrition, 130(9), 2285-2291.

Grummer, R. R. (1991). Effect of feed on the composition of milk fat. Journal of Dairy Science, 74(9), 3244-3257.

Haenlein, G. F. W. (2004). Goat milk in human nutrition. Small Ruminant Research, 51(2), $155-163$.

Halliwell, B., Zhao, K., \& Whiteman, M. (2000). The gastrointestinal tract: A major site of antioxidant action? Free Radical Research, 33(6), 819-830.

Hekmat, S., Soltani, H., \& Reid, G. (2009). Growth and survival of Lactobacillus reuteri RC14 and Lactobacillus rhamnosus GR-1 in yogurt for use as a functional food. Innovative Food Science \& Emerging Technologies, 10(2), 293-296.

Heller, K. J. (2001). Probiotic bacteria in fermented foods: Product characteristics and starter organisms. The American Journal of Clinical Nutrition, 73(2), 374-379.

Hervert-Hernández, D., Pintado, C., Rotger, R., \& Goñi, I. (2009). Stimulatory role of grape pomace polyphenols on Lactobacillus acidophilus growth. International Journal of Food Microbiology, 136(1), 119-122.

Hijova, E., \& Chmelarova, A. (2007). Short chain fatty acids and colonic health. Bratislavské Lekárske Listy, 108(8), 354-358.

Hill, C., Guarner, F., Reid, G., Gibson, G. R., Merenstein, D. J., Pot, B., ... Sanders, M. E. (2014). Expert consensus document: The International Scientific Association for Probiotics and Prebiotics consensus statement on the scope and appropriate use of the term probiotic. Nature Reviews. Gastroenterology \& Hepatology, 11, 506-514.

Hosseini, E., Grootaert, C., Verstraete, W., \& Van de Wiele, T. (2011). Propionate as a health-promoting microbial metabolite in the human gut. Nutrition Reviews, 69(5), 245-258.

Jenness, R. (1980). Composition and characteristics of goat milk: Review 1968 - 19791. Journal of Dairy Science, 63(10), 1605-1630.

Jia, R., Chen, H., Chen, H., \& Ding, W. (2016). Effects of fermentation with Lactobacillus rhamnosus GG on product quality and fatty acids of goat milk yogurt. Journal of Dairy Science, 99(1), 221-227.

Karaaslan, M., Ozden, M., Vardin, H., \& Turkoglu, H. (2011). Phenolic fortification of yogurt using grape and callus extracts. LWT - Food Science and Technology, 44(4), 1065-1072.

Kemperman, R. A., Bolca, S., Roger, L. C., \& Vaughan, E. E. (2010). Novel approaches for analysing gut microbes and dietary polyphenols: Challenges and opportunities. Microbiology, 156(11), 3224-3231.

Kemperman, R. A., Gross, G., Mondot, S., Possemiers, S., Marzorati, M., Van de Wiele, T., ... Vaughan, E. E. (2013). Impact of polyphenols from black tea and red wine/grape juice on a gut model microbiome. Food Research International, 53(2), 659-669.

Kremer, J. M., Lawrence, D. A., Jubiz, W., DiGiacomo, R., Rynes, R., Bartholomew, L. E., \& Sherman, M. (1990). Dietary fish oil and olive oil supplementation in patients with rheumatoid arthritis. Clinical and immunologic effects. Arthritis and Rheumatism, 33(6), 810-820.

Lara-Villoslada, F., Debras, E., Nieto, A., Concha, A., Gálvez, J., López-Huertas, E., Xaus, J. (2006). Oligosaccharides isolated from goat milk reduce intestinal inflammation in a rat model of dextran sodium sulfate-induced colitis. Clinical Nutrition, 25(3), 477-488.

Linos, A., Kaklamanis, E., Kontomerkos, A., Koumantaki, Y., Gazi, S., Vaiopoulos, G., .. Kaklamanis, P. (1991). The effect of olive oil and fish consumption on rheumatoid arthritis - a case control study. Scandinavian Journal of Rheumatology, 20(6), 419-426.

Lipworth, L., Martínez, M. E., Angell, J., Hsieh, C. C., \& Trichopoulos, D. (1997). Olive oil and human cancer: An assessment of the evidence. Preventive Medicine, 26(2), 181-190.

Lopez-Huertas, E. (2010). Health effects of oleic acid and long chain omega-3 fatty acids (EPA and DHA) enriched milks. A review of intervention studies. Pharmacological Research, 61(3), 200-207.

Lourens-Hattingh, A., \& Viljoen, B. C. (2001). Yogurt as probiotic carrier food. International Dairy Journal, 11(1-2), 1-17.

Manach, C., Hubert, J., Llorach, R., \& Scalbert, A. (2009). The complex links between dietary phytochemicals and human health deciphered by metabolomics. Molecular Nutrition \& Food Research, 53(10), 1303-1315.

Manach, C., Mazur, A., \& Scalbert, A. (2005). Polyphenols and prevention of cardiovascular diseases. Current Opinion in Lipidology, 16(1), 77-84.

Mañas, E., Bravo, L., \& Saura-Calixto, F. (1994). Sources of error in dietary fibre analysis. Food Chemistry, 50(4), 331-342.

Martin-Moreno, J. M., Willett, W. C., Gorgojo, L., Banegas, J. R., Rodriguez-Artalejo, F., Fernandez-Rodriguez, J. C., ... Boyle, P. (1994). Dietary fat, olive oil intake and breast cancer risk. International Journal of Cancer, 58(6), 774-780.

Marzorati, M., Wittebolle, L., Boon, N., Daffonchio, D., \& Verstraete, W. (2008). How to get more out of molecular fingerprints: Practical tools for microbial ecology. Environmental Microbiology, 10(6), 1571-1581.

Marzotto, M., Maffeis, C., Paternoster, T., Ferrrario, R., Rizzotti, L., Pellegrino, M., et al. (2006). Lactobacillus paracasei A survives gastrointestinal passage and affects the fecal microbiota of healthy infants. Research in Microbiology, 157, 857-866.
Matheson, B., Walker, K. Z., Taylor, D. M., Peterkin, R., Lugg, D., \& O'Dea, K. (1996). Effect on serum lipids of monounsaturated oil and margarine in the diet of an Antarctic Expedition. The American Journal of Clinical Nutrition, 63(6), 933-938.

Mertens, B., Boon, N., \& Verstraete, W. (2005). Stereospecific effect of hexachlorocyclohexane on activity and structure of soil methanotrophic communities. Environmental Microbiology, 7(5), 660-669.

Miles, E. A., \& Calder, P. C. (1998). Modulation of immune function by dietary fatty acids. Proceedings of the Nutrition Society, 57(2), 277-292.

Millar, M. R., Bacon, C., Smith, S. L., Walker, V., \& Hall, M. A. (1993). Enteral feeding of premature infants with Lactobacillus GG. Archives of Disease in Childhood, 69(5), $483-487$.

Minervini, F., Bilancia, M. T., Siragusa, S., Gobbetti, M., \& Caponio, F. (2009). Fermented goats' milk produced with selected multiple starters as a potentially functional food. Food Microbiology, 26(6), 559-564.

Molly, K., Woestyne, M. V., Smet, I. D., \& Verstraete, W. (1994). Validation of the Simulator of the Human Intestinal Microbial Ecosystem (SHIME) reactor using microorganism-associated activities. Microbial Ecology in Health and Disease, 7(4), 191-200.

Montalto, M., D'onofrio, F., Gallo, A., Cazzato, A., \& Gasbarrini, G. (2009). Intestinal microbiota and its functions. Digestive and Liver Disease Supplements, 3(2), 30-34.

Mortensen, P. B., \& Clausen, M. R. (1996). Short-chain fatty acids in the human colon: Relation to gastrointestinal health and disease. Scandinavian Journal of Gastroenterology, 31(216), 132-148.

Munoa, F. J., \& Pares, R. (1988). Selective medium for isolation and enumeration of Bifidobacterium spp. Applied and Environmental Microbiology, 54, 1715-1718.

Oliveira, M. N., Sodini, I., Remeuf, F., \& Corrieu, G. (2001). Effect of milk supplementation and culture composition on acidification, textural properties and microbiological stability of fermented milks containing probiotic bacteria. International Dairy Journal, 11(11 - 12), 935-942.

Pandey, K. B., \& Rizvi, S. I. (2009). Plant polyphenols as dietary antioxidants in human health and disease. Oxidative Medicine and Cellular Longevity, 2(5), 270-278.

Park, Y. W. (2007). Rheological characteristics of goat and sheep milk. Small Ruminant Research, 68(1-2), 73-87.

Possemiers, S., Marzorati, M., Verstraete, W., \& Van de Wiele, T. (2010). Bacteria and chocolate: A successful combination for probiotic delivery. International Journal of Food Microbiology, 141(1-2), 97-103.

Possemiers, S., Verthé, K., Uyttendaele, S., \& Verstraete, W. (2004). PCR-DGGE-based quantification of stability of the microbial community in a simulator of the human intestinal microbial ecosystem. FEMS Microbiology Ecology, 49(3), 495-507.

Pozuelo, M. J., Agis-Torres, A., Hervert-Hernández, D., López-Oliva, M. E., MuñozMartínez, E., Rotger, R., \& Goñi, I. (2012). Grape antioxidant dietary fiber stimulates Lactobacillus growth in rat cecum. Journal of Food Science, 77(2), 59-62.

Prasain, J. K., Carlson, S. H., \& Wyss, J. M. (2010). Flavonoids and age-related disease: Risk, benefits and critical windows. Maturitas, 66(2), 163-171.

Puupponen-Pimiä, R., Nohynek, L., Meier, C., Kähkönen, M., Heinonen, M., Hopia, A., \& Oksman-Caldentey, K. M. (2001). Antimicrobial properties of phenolic compounds from berries. Journal of Applied Microbiology, 90(4), 494-507.

Ran-Ressler, R. R., Bae, S., Lawrence, P., Wang, D. H., \& Brenna, J. T. (2014). Branchedchain fatty acid content of foods and estimated intake in the USA. British Journal of Nutrition, 112(4), 565-572.

Raynal-Ljutovac, K., Lagriffoul, G., Paccard, P., Guillet, I., \& Chilliard, Y. (2008). Composition of goat and sheep milk products: An update. Small Ruminant Research, $79(1), 57-72$.

Re, R., Pellegrini, N., Proteggente, A., Pannala, A., Yang, M., \& Rice-Evans, C. (1999). Antioxidant activity applying an improved ABTS radical cation decolorization assay. Free Radical Biology and Medicine, 26(9-10), 1231-1237.

Reid, G., Beuerman, D., Heinemann, C., \& Bruce, A. W. (2001). Probiotic Lactobacillus dose required to restore and maintain a normal vaginal flora. FEMS Immunology and Medical Microbiology, 32(1), 37-41.

Reid, G., \& Bruce, A. W. (2003). Urogenital infections in women: Can probiotics help? Postgraduate Medical Journal, 79, 428-432.

dos Reis, C. M., Carosia, M. F., Sakamoto, I. K., Varesche, M. B. A., \& Silva, E. L. (2015), Evaluation of hydrogen and methane production from sugarcane vinasse in an anaerobic fluidized bed reactor. International Journal of Hydrogen Energy, 40(27), 8498-8509.

Ríos-Covián, D., Ruas-Madiedo, P., Margolles, A., Gueimonde, M., De los Reyes-Gavilán, C. G., \& Salazar, N. (2016). Intestinal short chain fatty acids and their link with diet and human health. Frontiers in Microbiology, 7, 1-9.

Roberfroid, M., Gibson, G. R., Hoyles, L., McCartney, A. L., Rastall, R., Rowland, I., .. Meheust, A. (2010). Prebiotic effects: Metabolic and health benefits. British Journal of Nutrition, 104(S2), 1-63.

Saad, S. M. I. (2006). Probiotics and prebiotics: The state of the art. Revista Brasileira de Ciências Farmacêuticas, 42(1), 1-16.

Salva, S., Nuñez, M., Villena, J., Ramón, A., Font, G., \& Alvarez, S. (2011). Development of a fermented goats' milk containing Lactobacillus rhamnosus: In vivo study of health benefits. Journal of the Science of Food and Agriculture, 91(13), 2355-2362.

Sánchez-Patán, F., Barroso, E., Van De Wiele, T., Jiménez-Girón, A., Martín-Alvarez, P. J., Moreno-Arribas, M. V., ... Bartolomé, B. (2015). Comparative in vitro fermentations of cranberry and grape seed polyphenols with colonic microbiota. Food Chemistry, 183, 273-282.

Sanders, M. E. (2003). Probiotics: Considerations for human health. Nutrition Reviews, 61(3), 91-99.

Sanguinetti, C. J., Dias Neto, E., \& Simpson, A. J. (1994). Rapid silver staining and re covery of PCR products separated on polyacrylamide gels. BioTechniques, 17(5), 914-921.

dos Santos, K. M., de Oliveira, I. C., Lopes, M. A., Cruz, A. P. G., Buriti, F. C., \& Cabral, L. 
M. (2016). Addition of grape pomace extract to probiotic fermented goat milk: The effect on phenolic content, probiotic viability and sensory acceptability. Journal of the Science of Food and Agriculture, 97(4), 1108-1115.

Saxelin, M., Ahokas, M., \& Salminen, S. (1993). Dose response on the faecal colonisation of Lactobacillus strain GG administered in two different formulations. Microbial Ecology in Health and Disease, 6(3), 119-122.

Schneider, H., Schwiertz, A., Collins, M. D., \& Blaut, M. (1999). Anaerobic transformation of quercetin-3-glucoside by bacteria from the human intestinal tract. Archives of Microbiology, 171(2), 81-91.

Schoefer, L., Mohan, R., Schwiertz, A., Braune, A., \& Blaut, M. (2003). Anaerobic degradation of flavonoids by Clostridium orbiscindens. Applied and Environmental Microbiology, 69(10), 5849-5854.

Scott, K. P., Gratz, S. W., Sheridan, P. O., Flint, H. J., \& Duncan, S. H. (2013). The influence of diet on the gut microbiota. Pharmacological Research, 69(1), 52-60.

Sendra, E., Sayas-Barberá, M. E., Fernández-López, J., \& Pérez-Alvarez, J. A. (2016). Effect of food composition on probiotic bacteria viability. In R. R. Watson, \& V. R. Preedy (Eds.), Probiotics, Prebiotics, and Synbiotics (pp. 257-269). (2015).

Serpen, A., Capuano, E., Fogliano, V., \& Gökmen, V. (2007). A new procedure to measure the antioxidant activity of insoluble food components. Journal of Agricultural and Food Chemistry, 55(19), 7676-7681.

Silanikove, N., Leitner, G., Merin, U., \& Prosser, C. G. (2010). Recent advances in exploiting goat's milk: Quality, safety and production aspects. Small Ruminant Research, 89(2-3), 110-124.

Simonsen, N. R., Navajas, J. F.-C., Martin-Moreno, J. M., Strain, J. J., Huttunen, J. K., Martin, B. C., ... Kohlmeier, L. (1998). Tissue stores of individual monounsaturated fatty acids and breast cancer: The EURAMIC study. European Community Multicenter Study on Antioxidants, Myocardial Infarction, and Breast Cancer. The American Journal of Clinical Nutrition, 68(1), 134-141.

Sivieri, K., Morales, M. L. V., Saad, S. M. I., Adorno, M. A. T., Sakamoto, I. K., \& Rossi, E. A. (2014). Prebiotic effect of fructooligosaccharide in the Simulator of the Human Intestinal Microbial Ecosystem (SHIME ${ }^{\circledR}$ model). Journal of Medicinal Food, 17(8), 894-901.

Sun, J., Chu, Y. F., Wu, X., \& Liu, R. H. (2002). Antioxidant and antiproliferative activities of common fruits. Journal of Agricultural and Food Chemistry, 50(25), 7449-7454.

Tabasco, R., Sánchez-Patán, F., Monagas, M., Bartolomé, B., Victoria Moreno-Arribas, M., Peláez, C., \& Requena, T. (2011). Effect of grape polyphenols on lactic acid bacteria and bifidobacteria growth: Resistance and metabolism. Food Microbiology, 28(7), 1345-1352.

Tuo, Y., Zhang, W., Zhang, L., Ai, L., Zhang, Y., Han, X., \& Yi, H. (2013). Study of probiotic potential of four wild Lactobacillus rhamnosus strains. Anaerobe, 21, 22-27.

Tuohy, K. M., Conterno, L., Gasperotti, M., \& Viola, R. (2012). Up-regulating the human intestinal microbiome using whole plant foods, polyphenols, and/or fiber. Journal of Agricultural and Food Chemistry, 60(36), 8776-8782.

Uriot, O., Galia, W., Awussi, A. A., Perrin, C., Denis, S., Chalancon, S., ... Roussel, Y. (2016). Use of the dynamic gastro-intestinal model TIM to explore the survival of the yogurt bacterium Streptococcus thermophilus and the metabolic activities induced in the simulated human gut. Food Microbiology, 53, 18-29.

Van de Wiele, T., Boon, N., Possemiers, S., Jacobs, H., \& Verstraete, W. (2004). Prebiotic effects of chicory inulin in the simulator of the human intestinal microbial ecosystem. FEMS Microbiology Ecology, 51(1), 143-153.

Van Duynhoven, J., Vaughan, E. E., Jacobs, D. M., Kemperman, R. A., Van Velzen, E. J., Gross, G., ... Westerhuis, J. A. (2011). Metabolic fate of polyphenols in the human superorganism. Proceedings of the National Academy of Sciences, 108, 4531-4538 (Supplement 1).

Wittebolle, L., Vervaeren, H., Verstraete, W., \& Boon, N. (2008). Quantifying community dynamics of nitrifiers in functionally stable reactors. Applied and Environmental Microbiology, 74(1), 286-293.

Wongtangtintharn, S., Oku, H., Iwasaki, H., \& Toda, T. (2004). Effect of branched-chain fatty acids on fatty acid biosynthesis of human breast cancer cells. Journal of Nutritional Science and Vitaminology, 50(2), 137-143.

Wu, G. D., Chen, J., Hoffmann, C., Bittinger, K., Chen, Y., Sue, A., ... Li, H. (2012). Linking long-term dietary patterns with gut microbial Enterotypes. Science, 334(6052), 105-108.

Yang, Z., Liu, S., Chen, X., Chen, H., Huang, M., \& Zheng, J. (2000). Advances in brief induction of apoptotic cell death and in vivo growth inhibition of human cancer cells by a saturated branched-chain fatty acid, 13-methyltetradecanoic acid. Cancer Research, 60(3), 505-509.

Yaqoob, P. (1998). Monounsaturated fats and immune function. Brazilian Journal of Medical and Biological Research, 31(4), 453-465.

Yoshioka, H., Iseki, K., \& Fujita, K. (1983). Development and difference of intestinal flora in the neonatal period in breast-fed and bottle-fed infants. Pediatrics, 72, 317-321. 